\title{
Distinguishing Between Heterogeneity and Inefficiency: Stochastic Frontier Analysis of the World Health Organization's Panel Data on National Health Care Systems
}

\author{
William Greene* \\ Department of Economics, Stern School of Business, \\ New York University,
}

April 20, 2003

\begin{abstract}
The most commonly used approaches to parametric (stochastic frontier) analysis of efficiency in panel data, notably the fixed and random effects models, fail to distinguish between cross individual heterogeneity and inefficiency. This blending of effects is particularly problematic in the World Health Organization's (WHO) panel data set on health care delivery, which is a 191 country, five year panel. The wide variation in cultural and economic characteristics of the worldwide sample of countries produces a large amount of unmeasured heterogeneity in the data. Familiar approaches to inefficiency estimation mistakenly measure that heterogeneity as inefficiency. This study will examine a large number of recently developed alternative approaches to stochastic frontier analysis with panel data, and apply some of them to the WHO data. A more general, flexible model and several measured indicators of cross country heterogeneity are added to the analysis done by previous researchers. Results suggest that in these data, there is considerable evidence of heterogeneity that in other studies using the same data, has masqueraded as inefficiency. Our results differ substantially from those obtained by several earlier researchers.
\end{abstract}

Keywords: Panel data, fixed effects, random effects, random parameters, technical efficiency, stochastic frontier, heterogeneity, health care.

JEL classification: $\mathrm{C} 1, \mathrm{C} 4$

\footnotetext{
* 44 West $4^{\text {th }}$ St., New York, NY 10012, USA, Telephone: 001-212-998-0876; fax: 01-212-995-4218; email: wgreene@stern.nyu.edu, URL www.stern.nyu.edu/ wgreene. Elements of this paper have been presented at the conference on "Current Developments in Productivity and Efficiency Measurement," University of Georgia, October 25-26, 2002 and the Second Hellenic Workshop on Productivity and Efficiency Measurement in Patras Greece, May 30, 2003. It has also benefited from comments at the North American Productivity Workshop at Union College, June, 2002, the Asian Conference on Efficiency and Productivity in Taipei in July, 2002 and from discussions at The University of Leicester, York University and Binghamton University and ongoing conversations with Mike Tsionas, Subal, Kumbhakar and Knox Lovell.
} 


\section{Introduction}

The World Health Report 2000 (WHR) [WHO (2000)] is a large, worldwide assessment of the effectiveness of health care delivery. Among other analyses, the study presents a rankings based comparison of the productive efficiency of the health care systems of 191 countries. ${ }^{1}$ Predictably, the attention focused on these rankings has been considerably out of proportion to the space this section occupies in the larger report itself.

The rankings were produced using a form of the "fixed effects," stochastic frontier methodology proposed by Schmidt and Sickles (1984) and Cornwell, Sickles and Schmidt (1990) [see Evans et al. (2000a,b)] $(E T M L)$. The data analyzed in this econometric study were a five year (1993-1997) panel. This section of the WHR has been heavily criticized for numerous reasons related to the overall objectives, the quality and validity of the effectiveness measures, the input data used, and the appropriateness of the methodology. [See, e.g., Gravelle et al. (2002a,b) (GJJS), Williams (2001) and Hollingsworth and Wildman (2002) $(H W)$.] On January 8, 2001, coincident with the 2001 meeting of the Allied Social Science Association in New Orleans, the authors of the frontier study convened a panel of researchers specifically to discuss the econometric methodology. ${ }^{2}$ The focus of the meeting was the use of panel data, such as those in the WHR study, for measurement of efficiency in health care delivery. This paper reports subsequent research undertaken to study some of the issues raised at that meeting.

One criticism of the fixed effects methodology used (and several other related approaches) is that the model fails to distinguish between cross country heterogeneity unrelated to inefficiency and the inefficiency itself. This ambiguity is likely to be especially problematic in these data, as they are based on 191 sometimes vastly different countries; France, England and Australia appear in the sample on equal terms with Oman, Sri Lanka, Zimbabwe, the Seychelles, Colombia and Bangladesh. We undertook to examine this issue, to reanalyze the WHO data and the methods used in the study, and to propose alternative stochastic frontier based methods with greater flexibility that will allow the analyst to segregate individual, unmeasured heterogeneity and technical or cost inefficiency.

The paper is organized as follows: Section 2 reviews the WHO methodology and takes a cursory look at their results. The stochastic frontier model and strategies for modeling panel data are reviewed in Section 3. ${ }^{3}$ The WHO data that were used in this study as well are described in Section 4. The several studies of the WHO data [ETML (2000a,b), HW (2002), GJJS. (2002b)] that we examined were based on two output measures, a composite measure of health care delivery (COMP) and disability adjusted life expectancy (DALE) and two inputs, health care expenditure and education levels. In this study, we consider how to use additional covariates in the data set including per

\footnotetext{
${ }^{1}$ The numerical values on which the rankings are based do not have a clear interpretation. The studies focus on the rankings, and contain only minor discussion of the quantitative efficiency measures.

${ }^{2}$ See WHO (2001). The participants were, in addition to Evans, et al., were William Greene of NYU, Subal Kumbhakar, University of Binghamton, Knox Lovell, University of Georgia, Kaliappa Kalirajan, ANU, Marijn Berhoeven, IMF, Paul Wilson, University of Texas, Christopher Tong, Hong Kong Baptist University and Philip Grossman, St. Cloud State University.

${ }^{3}$ We have focused on parametric and semiparametric stochastic frontier models. Nonparametric methods such as data envelopment analysis (DEA) are not considered here. [For commentary, see, e.g., Hollingsworth and Wildman (2002).]
} 
capita income, income distribution, government effectiveness, and the allocation of health care expenditure between the public and private sectors to account for some of the heterogeneity noted earlier. ${ }^{4}$ The empirical results are presented in Section 5 . We begin with an examination of the production function used, and propose some results that are in broad agreement with others already in the literature regarding the impact of income and the distribution of income on health care outcomes. The second set of results will compare fixed and random effects estimates of technical inefficiency. We find that concerns of ETML $(2000 \mathrm{a}, \mathrm{b})$ notwithstanding, for these data, a form of the random effects model appears to be a satisfactory framework for analyzing the WHO data. We then incorporate the country specific heterogeneity in the estimated distribution of technical inefficiency, then in addition, in the production function itself. Our alternative results are presented here and in the Appendices. This section also proposes some recently developed panel data techniques which, though promising for research in this area, for practical reasons, do not appear to be appropriate for the WHO data. Some conclusions are drawn in Section 6.

\footnotetext{
${ }^{4}$ Per capita income was briefly considered in each of these, but did not play a central role in any of the empirical analyses.
} 


\section{The WHO Studies of Health Care Attainment}

Health policy makers are concerned with overall health system performance. Reforms are directed at all functions in the health system including financing, provision of services, management, and so on. Evaluation of the effectiveness of policies and reforms faces two large obstacles, quantifying goals and objectives so that outcomes can be measured and enumerating inputs in a way that resources can be directed toward them so as to achieve those objectives. The effectiveness study in the WHR is an attempt to measure health care effectiveness in a production function framework. Superficially, the setting lends itself well to that framework, with one substantive variation. In the textbook case of a production technology, zero inputs implies zero output. But, no matter how the outcome is defined, output of the "health care system" of a country would not be zero even if no resources were directed toward the health sector - \{“i.e., the entire population would not be dead" [Evans et al. (2000a, page 2.)]\}. This view is summarized in Figure 1, which is taken from ETML. (2000a, page. 2).

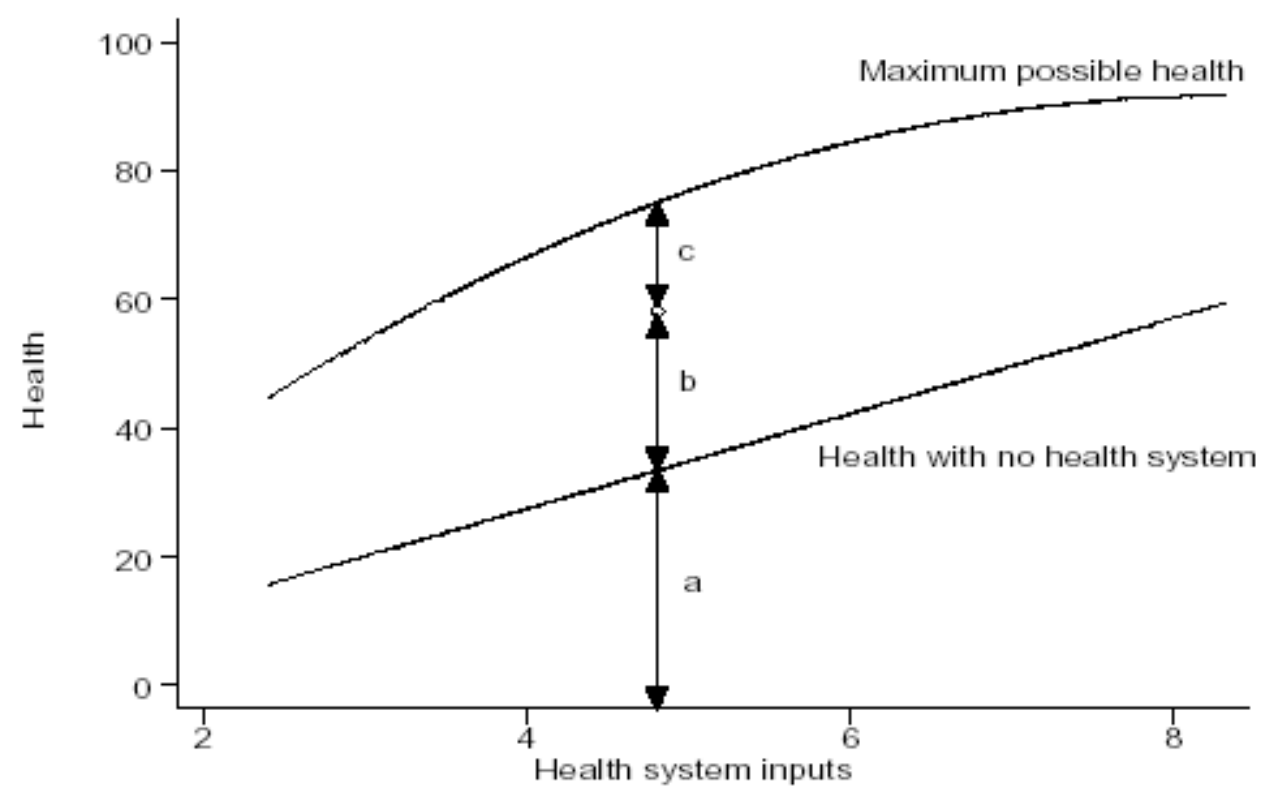

Figure 1: Health System Performance

The authors rejected several common methodologies as frameworks for modeling health system performance. Nonparametric data envelopment analysis and "free disposal hull" methods were criticized for their inability to accommodate random variation in the data. Corrected least squares [Greene (1997)] does not account for the fact that the production function is an upper bound. Finally, the stochastic frontier model [Aigner, Lovell and Schmidt (1977)] was deemed to be unduly stringent in its imposition of a specific distributional assumption on the inefficiency component of the model. ETML's (2000a,b) preferred methodology was a "panel data," production function estimator based on the framework proposed by Schmidt and Sickles (1984) and Cornwell et al. (1990). 
The central feature of the estimator is a fixed effects linear regression model. It is argued that this approach brings gains in statistical efficiency while obviating assumptions about the distribution of technical inefficiency. ${ }^{5}$

The production function is denoted

$$
y_{i t} \quad=\alpha+\mathbf{x}_{i t}{ }^{\prime} \beta+v_{i t}-u_{i}
$$

where $y_{i t}$ is the (log of the) output of the system, $\mathbf{x}_{i t}$ is (logs of) the set of inputs, $v_{i t}$ is the random component representing stochastic elements as well as any country (and time) specific heterogeneity, $u_{i}$ is the inefficiency in the system, and $i$ and $t$ denote country and year, respectively. Consistent with the objectives of the study (and Figure 1), it is assumed that $u_{i}>0$. The equation is rewritten

$$
\begin{aligned}
y_{i t} \quad & =\left(\alpha-u_{i}\right)+\mathbf{x}_{i t}{ }^{\prime} \beta+v_{i t} \\
& =\alpha_{i}+\mathbf{x}_{i t}{ }^{\prime} \beta+v_{i t} .
\end{aligned}
$$

Assuming that $v_{i t}$ has the familiar stochastic properties of a regression model and is uncorrelated with other components of the model, the parameters can be estimated by least squares, using the "within," or dummy variable estimator. The country specific constants embody the technical inefficiency. The inefficiencies are estimated in turn by shifting the function upward so that each constant term is measured as a deviation from the benchmark level;

$$
\hat{u}_{i} \quad=\max _{i}\left(\hat{\alpha}_{i}\right)-\hat{\alpha}_{i} \geq 0 \text {. }
$$

(Note that by this construction, one country is measured as $100 \%$ efficient.) Technical efficiency is now measured by

$$
T E_{i}=\frac{E\left[y_{i t} \mid \mathbf{x}_{i t}, u_{i}\right]}{E\left[y_{i t} \mid \mathbf{x}_{i t}, u_{i}=0\right]}
$$

Overall efficiency is constructed by normalizing this measure to a constructed minimum level of output that would (more or less) correspond to a system with zero inputs;

$$
E_{i}=\frac{E\left[y_{i t} \mid \mathbf{x}_{i t}, u_{i}\right]-M_{i t}}{E\left[y_{i t} \mid \mathbf{x}_{i t}, u_{i}=0\right]-M_{i t}} .
$$

\footnotetext{
${ }^{5}$ The authors also rejected the random effects model based on the results of a Hausman specification test. It should be noted that the random effects regression model would have been counterproductive as, unlike the fixed effects model, it does not provide a readily computed estimate of the firm specific term that is the central focus of the study. We will return to this specification issue later in the text.

${ }^{6}$ The definition of $M_{i t}$ used differs in the two studies. In both cases, it was based on the disability adjusted life expectancy (DALE) measured in a sample of 25 countries around 1908, at a time and in places where it was felt that the influence of health service inputs on health care would have been minimal. See ETML (2000a, p. 14 and 2000b, pp. 6 and 8) for definitions.
} 
In Figure 1, $T E_{i}$ would give for each country, the ratio $(a+b) /(a+b+c)$ while $E_{i}$ would measure $b /(b+c)$.

Empirical analysis in the two studies used as inputs per capita public and private health care expenditure $(E X P)$ and average years of education of the population $(E D U C)$. Two measures of health care attainment were analyzed, disability adjusted life expectancy $(D A L E)$ and a composite measure of health care delivery $(C O M P)$. The production function employed in both cases was

$$
y_{i t}=\alpha_{i}+\beta_{1} \log E X P_{i t}+\beta_{2} \log E D U C_{i t}+\beta_{3} \log ^{2} E D U C_{i t}+v_{i t}
$$

where $y_{i t}$ is the log of DALE in ETML (2000a) and the log of COMP in (2000b). (Greater detail on these is given below.) Figure 2 [Figure 6 from ETML (2000a)] illustrates the overall results for the first analysis.

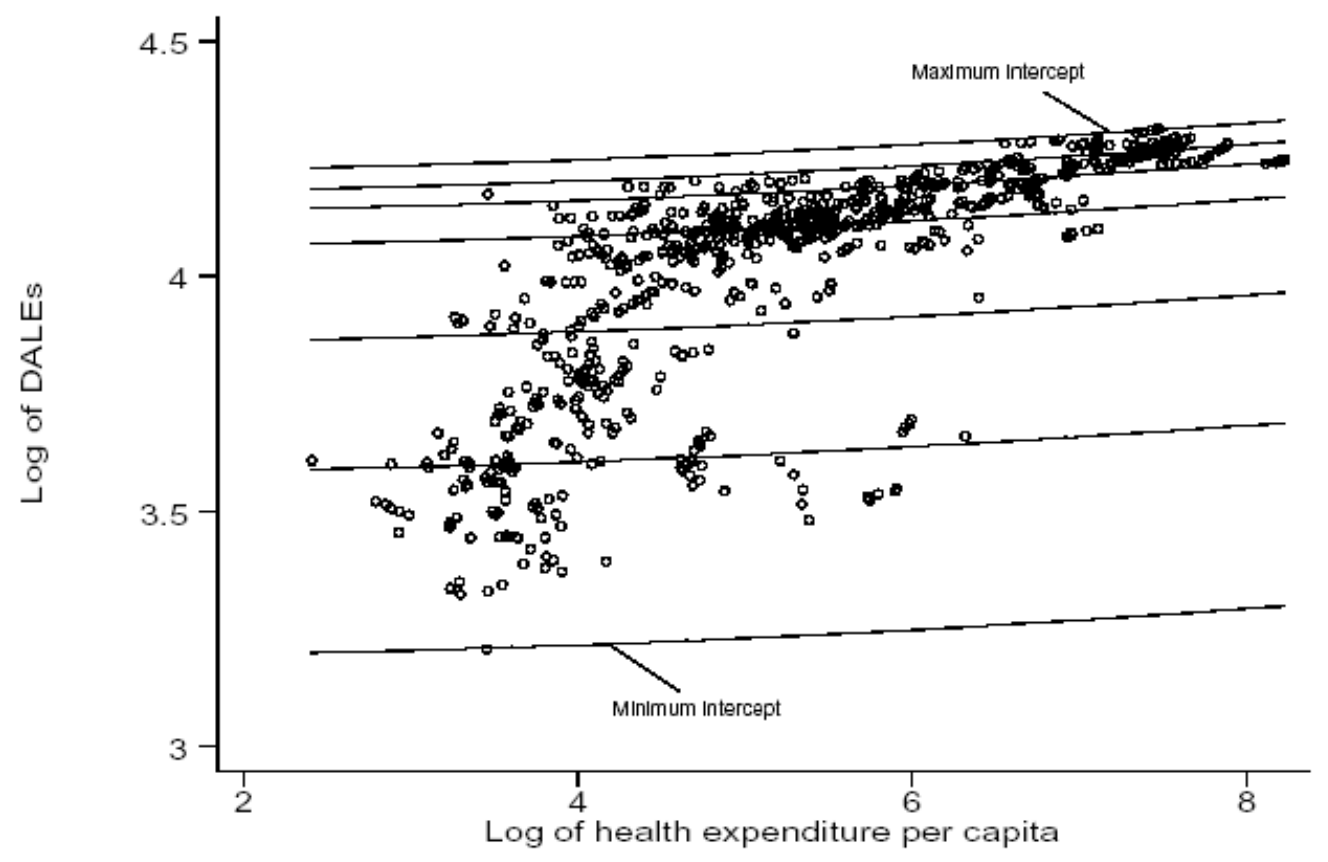

Figure 2: Estimated Efficiencies Based on DALE for 191 Countries

Table 1 shows some of the estimated results from the two studies. The specific numeric values for DALE, in years, have a ready interpretation, but those for COMP have no clear numeraire. In principle, each $T E_{i}$ gives $b /(b+c)$ in Figure 1, or the percentage of maximal output above the minimum that is attained in the country. Based on the numeric values of the attainment measures, these would give the proportional potential for improvement. As noted, the focus of the studies was the rankings, not the numeric values. (Among the criticisms of the study is the lack of a clear understanding of how one might make use of these rankings. To some extent - this is suggested in the text - these studies were viewed as innovative first steps, not definitive answers to any specific question.) We note, finally, even the figures given suggest the potential for improvement in essentially 
qualitative terms, especially for the COMP measure. The authors did not adopt a cost function methodology. In a cost frontier, the measured inefficiency would have implied, given observable expenditure data, a quantifiable and probably unbearable burden for large numbers of already poor countries. Of course, this raises the question noted earlier. How the results of this study or others like it can be translated into policy is an important and yet unanswered question.

Table 1: Selected WHO Estimates of Overall Efficiency

\begin{tabular}{|l|l|c|l|c|}
\hline \multicolumn{2}{|c|}{ Country $^{|c|}$ Rank } & \multicolumn{2}{c|}{ COMP $^{\mathbf{b}}$} \\
\hline $\mathbf{1}$ & \multicolumn{1}{|c|}{ Country } & E \\
\hline $\mathbf{2}$ & Oman & 0.992 & France & 0.994 \\
\hline $\mathbf{3}$ & Malta & 0.989 & Italy & 0.991 \\
\hline $\mathbf{4}$ & Italy & 0.976 & San Marino & 0.988 \\
\hline $\mathbf{5}$ & France & 0.974 & Andorra & 0.982 \\
\hline $\mathbf{2 5}$ & San Marino & 0.971 & Malta & 0.978 \\
\hline $\mathbf{5 0}$ & Costa Rica & 0.882 & Germany & 0.902 \\
\hline $\mathbf{1 0 0}$ & Uruguay & 0.819 & Poland & 0.793 \\
\hline $\mathbf{1 5 0}$ & Jordan & 0.711 & St. Kitts and Nevis & 0.643 \\
\hline $\mathbf{1 8 7}$ & Afghanistan & 0.517 & Nepal & 0.457 \\
\hline $\mathbf{1 8 8}$ & Malawi & 0.196 & Nigeria & 0.176 \\
\hline $\mathbf{1 8 9}$ & Botswana & 0.183 & Dem. Rep. of Congo & 0.171 \\
\hline $\mathbf{1 9 0}$ & Namibia & 0.183 & Central African Rep. & 0.156 \\
\hline $\mathbf{1 9 1}$ & Zambia & 0.112 & Myanmar & 0.138 \\
\hline & Zimbabwe & 0.080 & Sierra Leone & 0.000 \\
\hline & United Kingdom (24) & 0.883 & United Kingdom (18) & 0.925 \\
\hline
\end{tabular}

${ }^{a}$ From Evans et al. (2000a), Appendix

brom Evans (2000b), Annex, Table 1.

These data have been reanalyzed by several authors. A variety of strident criticisms were raised in Williams (2001), who questioned the methodology and objectives of the entire study as well as the quality of the data set and the appropriateness of the outcome measures. Several econometric studies have placed the first (DALE) study under narrower scrutiny. The second (COMP) has until now not been similarly examined.

Gravelle et al. (GJJS) (2000a,b) observed that in the sample of 191 countries, actually 51 of the data sets are observed for only one year (1997). As such, in computation of the fixed effects estimator, these countries fall out of the least squares sums. This implies that the estimates are actually based on these 140 countries, not 191, and the results for the 51 countries in question are computed from a model that is not based on them. This, in itself, does not necessarily taint the results if these observations are not systematically different from the others, but GJJS argue that they are, indeed different - they have lower health expenditures. Since the model is conditioned on health expenditure, this still does not cast doubt on the results; it does so only if the relationship between expenditure and DALE is systematically different, which is possible, but remains to be shown. Since the models estimated here involve all the data, we leave this question aside for future research. More troublesome is GJJS's observation that $99.8 \%$ 
of the variation in the log of the DALE variable is between, rather than within the groups (countries). The counterparts for the logs of expenditure (EXP) and education (EDUC) are $98.9 \%$ and $99.8 \%$, respectively. Thus, there is very little actual "panel data" variation in these data - it is essentially a cross section. GJJS proceeded to fit several models based on the "between" estimators (group means) and computed alternative adjusted measures of efficiency. They found varying degrees of correlation between their rankings and those in ETML (2000a), ranging from 0.97 down to about 0.39. [See their Table 2.] This suggests, as we find below, that the specification can make a considerable amount of difference in the results. (GJJS also argued for inclusion of time effects and other expenditure (income minus health expense) in the model. We will return to the model specification in Section 5.)

Hollingsworth and Wildman (2002) $(H W)$ also revisited the DALE results. They redid the computations using the nonparametric, data envelopment methods rejected by ETML. They also fit fixed effects models that extended the WHO formulation by allowing time variation in the constants of the form

$$
\alpha_{i t}=\theta_{1 i}+\theta_{2 i} t+\theta_{3 i} t^{2} .
$$

[See Cornwell et al. (1990).] The computation was done by regressing least squares residuals for each country on a constant, time, and its square. (This restricts attention to the balanced panel of the 140 countries observed in all five years. $)^{7}$ Finally, $H W$ fit separate stochastic frontier models for each year, and computed technical inefficiency estimates for each country for each year. In all cases, the results obtained were fairly similar to the WHO results, though some moderately large differences did emerge. $H W$ directed considerable attention to the differences between OECD and non-OECD countries in their results. Perhaps not surprisingly, their results suggest that these differences are large enough that one might want to analyze these groups separately. (Our result also suggest marked differences between the OECD and non-OECD countries.)

\footnotetext{
${ }^{7}$ Hollingsworth and Wildman (2002) argue that these estimates are consistent for increasing $T$, which would generally be the case, but in this setting, $T$ is only 5 , and is assumed to be fixed. The sampling variances of these country specific estimators are likely to be quite high. As they are crucial determinants of the quantity of greatest interest here, this is an important consideration.
} 


\section{The Stochastic Frontier Model}

The authors of the WHO analyses questioned the distributional assumptions in the stochastic frontier formulation. However, both GJJS and $H W$ found considerable similarity in the results across a number of different formulations. This suggests that specific assumptions about the distribution of efficiencies may be less restrictive than these views suggest. In addition, we submit that the formulations examined before were narrower than they could have been, and the stochastic frontier model allows the incorporation of cross country heterogeneity in several ways that are likely to bring large benefits in analyzing data as disparate as these. This section will lay out the stochastic frontier model in some detail. The basic formulation of the model is well documented in many sources - we suggest Kumbhakar and Lovell (2000) - so our description will be brief. We will then detail several panel data formulations, some of which have appeared in received work for some time, but several others that are quite new.

\subsection{Cross Section Variants}

The essential form of the stochastic production frontier model [see Aigner et al. (1977)] is

$$
\begin{aligned}
y_{i} & =\alpha+\mathbf{x}_{i}{ }^{\prime} \beta+v_{i}-u_{i} \\
v_{i} & \sim \mathrm{N}\left[0, \sigma_{v}{ }^{2}\right] \\
u_{i} & =\left|U_{i}\right|, \\
U_{i} & \sim \mathrm{N}\left[0, \sigma_{u}{ }^{2}\right]
\end{aligned}
$$

This is the canonical 'half normal' model. A central parameter in the model is the asymmetry parameter, $\lambda=\sigma_{u} / \sigma_{v}$; the larger is $\lambda$, the greater is the inefficiency component in the data. Parameters are estimated by maximum likelihood, rather than least squares. As in the earlier applications discussed here, estimation of $u_{i}$ is the central focus of the analysis. With the model estimated in logarithms, $u_{i}$ would correspond (to a small degree of approximation) to $1-T E_{i}$ given earlier. Individual specific efficiency is typically estimated with $\exp \left(-\hat{u}_{i}\right)$. Alternatively, $\hat{u}_{i}$, itself, provides an estimate of proportional inefficiency. With parameter estimates in hand, one can only obtain a direct estimate of $\varepsilon_{i}$ $=v_{i}-u_{i}$. This is translated into an estimate of $u_{i}$ using Jondrow et al.'s (JLMS) (1982) formula,

$$
\mathrm{E}\left[u_{i} \mid \varepsilon_{i}\right]=\frac{\sigma \lambda}{1+\lambda^{2}}\left[z_{i}+\frac{\phi\left(z_{i}\right)}{\Phi\left(z_{i}\right)}\right], z_{i}=-\varepsilon_{i} \lambda / \sigma
$$

where $\sigma=\left(\sigma_{u}{ }^{2}+\sigma_{v}{ }^{2}\right)^{1 / 2}$ and $\phi(z)$ and $\Phi(z)$ are the density and CDF of the standard normal distribution, respectively. 
The narrow assumption of half normality is a viewed as significant drawback in this model. ${ }^{8} H W$ and others [see Stevenson (1980)] have extended it to a truncated normal model by allowing the mean of $U_{i}$ to be nonzero. This is a useful extension in itself (though $H W$ find it makes little difference in their results). However, this extension stops short of a crucial step. The major shortcoming here is that the strict assumption suppresses individual heterogeneity in inefficiency that is allowed, for example, by the fixed effects formulation. But, as noted below, we have several indicators of this heterogeneity, such as income distribution, per capita income, OECD membership, the public share of health care expenditures, etc., and these can be incorporated into the distribution of $u_{i}$ in ways that the other methods already discussed cannot accommodate. Letting $\mathbf{h}_{i}$ denote a set of variables that measure the group heterogeneity, we write

$$
\mathrm{E}\left[U_{i}\right]=\mu_{i}=\mathbf{h}_{i}{ }^{\prime} \delta
$$

The Jondrow et al. result is now changed by replacing $z_{i}$ with $z_{i}^{*}=z_{i}-\mu_{i} /(\sigma \lambda)$. With data on indicators of heterogeneity in hand, this represents a significant extension of the model. ${ }^{9}$

Analysts frequently subject inefficiency estimates to a second step analysis. Thus, one might explore whether per capita income or the Gini measure of income inequality provide any explanatory power in the variation of the inefficiency measures. Arguably, if such covariates do have explanatory power, then they should appear in the model at the first step (to avoid biases due to "left out variables"). [See Wang and Schmidt (2002).] Among the methods considered so far, only the truncated normal stochastic frontier in $(8,10)$ can accommodate this sort of extension. Note, in particular, that if the covariates are time invariant, as is likely, then they cannot appear in the fixed effects model analyzed by ETML.

\subsection{Panel Data Formulations}

\section{The Fixed Effects Model}

The Schmidt and Sickles formulation,

$$
\begin{array}{ll}
y_{i t} & =\left(\alpha-u_{i}\right)+\mathbf{x}_{i t}{ }^{\prime} \beta+v_{i t} \\
& =\alpha_{i}+\mathbf{x}_{i t}{ }^{\prime} \beta+v_{i t} \\
\hat{u}_{i} & =\max _{i}\left(\hat{\alpha}_{i}\right)-\hat{\alpha}_{i} \geq 0,
\end{array}
$$

\footnotetext{
${ }^{8}$ Other distributional assumptions have been suggested, such as the normal-exponential [ALS (1977)] and the normal-gamma [Greene (1990, 2003a)]. These extensions occasionally bring noticeable changes in the results. But they are tangential for present purposes.

${ }^{9}$ Heteroscedasticity, of the form $\sigma_{u i}{ }^{2}=\exp \left(\mathbf{h}_{i}{ }^{\prime} \gamma\right)$ can also be incorporated in the model without great difficulty. Whether this is an equally beneficial extension remains to be established, and is left for further research.
} 
has been used in a number of applications. [See Wang and Schmidt (2002).] There are two important restrictions built into this model. First, any time invariant heterogeneity will be pushed into $\alpha_{i}$ and ultimately into $\hat{u}_{i}$. The WHO data span a tremendous range of cultures, economies, and policy settings. This is likely to be a particularly influential aspect of the model for these data. Second, the model (and some others we will consider) assumes that inefficiency is, itself, time invariant. For short time intervals, this may be a reasonable assumption. But, five years may be long enough for this to be questionable. $H W$ did find evidence to suggest that this assumption may be inconsistent with the data.

Both of these restrictions can be relaxed by placing country specific constant terms in the stochastic frontier model - we call this a 'true' fixed effects model.

$$
y_{i t} \quad=\alpha_{i}+\mathbf{x}_{i t}{ }^{\prime} \beta+v_{i t}-u_{i t}
$$

where $u_{i t}$ has the stochastic specifications noted earlier for the stochastic frontier model. Superficially, this amounts simply to adding a full set of country dummy variables to the stochastic frontier model. The model is still fit by maximum likelihood, not least squares. Surprisingly, this has hardly been used previously ${ }^{10}$ in spite of the fact that most of the received panel data applications involved fairly small panels. ${ }^{11}$

The true fixed effects model places the unmeasured heterogeneity in the production function; with a loglinear model, it produces a neutral shift of the function, specific to each country. One might, instead, have the heterogeneity reside in the inefficiency distribution. This could be accomplished with the formulation

$$
\mu_{i} \quad=\delta_{0 i}+\mathbf{h}_{i}{ }^{\prime} \delta
$$

that is, by placing the country specific dummy variables in the mean of the truncated normal distribution, rather than in the production function. Once again, in a moderate sized sample, this is a minor reformulation of the familiar model. The problems noted in the next paragraph will appear, but how serious these are is an empirical issue, nor a foregone conclusion.

The true fixed effects model has the virtues mentioned above. Weighing against it are, first, the incidental parameters problem and second, the possibility that the model is now overspecified. The incidental parameters problem [Lancaster (2000)] is a persistent bias that arises in nonlinear fixed effects models when the number of periods is small. (Five is small.). It has been widely documented for binary choice models [see, e.g., Hsiao (1996) and Greene (2002b)] but not systematically examined in stochastic frontier models. In Greene (2002a), we found that the biases in coefficient estimates were surprisingly small and did not appear in the patterns predicted by received results for other models, and, moreover, that there appeared to be no biases transmitted to the estimates of technical inefficiency. The second problem is now that the model may be

\footnotetext{
${ }^{10}$ The only received application of a type of true fixed effects model in the frontiers literature is Polachek and Yoon's (1996) study of labor supply.

${ }^{11}$ A major practical obstacle to use of the fixed effects approach in nonlinear models such as this one is the difficulty of computing the possibly hundreds or thousands of dummy variable coefficients. See Greene (2001) for analysis of the solution to this computational problem and Greene (2002b) for an application involving direct computation of models with tens of thousands of dummy variable coefficients.
} 
overspecified. If there is persistent inefficiency, it is now completely absorbed in the country specific constant term which is also capturing any time invariant heterogeneity. Whereas the earlier fixed effects form would tend to overestimate the inefficiency component, it is possible that this form will underestimate it. (This appears to be the case with the WHO data.) Unfortunately, this blending of the two effects is inherent in the modeling problem, and there is no simple solution that will be entirely satisfactory. Ultimately, $\alpha_{i}+v_{i t}-u_{i}$ contains both country specific heterogeneity and inefficiency, and both may have invariant and time varying elements. There is no perfect way to disentangle them based on observed data.

\section{The Random Effects Model}

The random effects model is obtained by assuming that $u_{i}$ is time invariant and also uncorrelated with the included variables in the model,

$$
y_{i t} \quad=\alpha+\mathbf{x}_{i t}{ }^{\prime} \beta+v_{i t}-u_{i}
$$

In the linear regression case analyzed by ETML, the parameters are estimated by two step generalized least squares. [See Greene (2003, chapter 11).] On the basis of a Hausman specification test, ETMA concluded that the random effects model would not be appropriate for their data. (Their test was conducted in a model that did not include any of the observed country specific effects, so the result may have been more convincing than appropriate. We will examine a more extensive specification below.) However, even if not, the regression based random effects model has a significant drawback for present purposes; there is no implied estimator of inefficiency in this model, that is, no estimator of $T E_{i}$ as in the fixed effects case. So, the model would not have been useful in any event.

Pitt and Lee (1981) showed how the time invariant composed error model could be extended to a panel data version of the stochastic frontier model. The direct extension would be of limited usefulness here, first because of the assumption of uncorrelatedness of $u_{i}$ and $\mathbf{x}_{i}$ and, once again, because of the assumption of time invariance of the inefficiency. The first of these can be remedied in the same fashion as suggested earlier. Estimation of the random effects model with heterogeneity in $\mathrm{E}\left[U_{i}\right]$, see (10), is straightforward. [See Econometric Software, Inc. (2002).] With this extension, the JLMS estimator becomes

$$
\mathrm{E}\left[u_{i} \mid \varepsilon_{1}, \varepsilon_{2}, \ldots, \varepsilon_{T}, \mathbf{h}_{i}\right]=Z_{i}+\psi\left[\frac{\phi\left(Z_{i} / \psi\right)}{\Phi\left(Z_{i} / \psi\right)}\right]
$$

where $Z_{i}=\gamma \mu_{i}-(1-\gamma) \bar{\varepsilon}_{i}, \gamma=1 /\left(1+T \lambda^{2}\right), \psi^{2}=\gamma \sigma_{\mathrm{u}}^{2}$, and $\bar{\varepsilon}_{i}=(1 / \mathrm{T}) \Sigma_{i} \varepsilon_{i t}{ }^{12}$

The time invariance of the inefficiency component of the random effects model is a potential drawback in the random effects model. Battese and Coelli $(B C)(1988,1995)$

\footnotetext{
${ }^{12}$ A minor adjustment must be made at this point for 'unbalanced' panels, that is data sets in which the number of observations, $T$, varies across individuals (countries). The adjustment is minor; in (15), $\psi$ becomes $\psi_{i}$ because it is now a function of the individual specific $T_{i}$. It is otherwise unchanged.
} 
have proposed a modification of the model that allows some systematic variation in the model;

$$
u_{i t} \quad=\eta_{t}\left|U_{i}\right|
$$

where $\eta_{t}=1+\eta_{1}(t-T)+\eta_{2}(t-T)^{2}$ and $U_{i} \sim \mathrm{N}\left[\mu, \sigma_{u}{ }^{2}\right]$. Various other forms of the function $\eta_{t}$ have been proposed, such as $\eta_{t}=\exp [-\eta(t-T)]$. [See $B C(1995, \mathrm{p}$. 1995) for discussion.] Kumbhakar and Orea (2003) suggest a more general form, $\eta_{i t}=\exp \left(\mathbf{g}_{i t}{ }^{\prime} \pi\right)$ which subsumes $B C$ 's formulation as well as many others. Greene (2003c) added the heterogeneous truncation form, $\mathrm{E}\left[U_{i}\right]=\mu_{i}$ to this as well. Let $\eta_{i}=\left(\eta_{i 1}, \eta_{i 2}, \ldots, \eta_{i T}\right)$ and $\varepsilon_{i}=$ $\left(\varepsilon_{i 1}, \varepsilon_{i 2}, \ldots, \varepsilon_{i T}\right)$. Estimates of technical inefficiency based on this model follow the same form as those in the Pitt and Lee model, where $Z_{i}$ is now

$$
Z_{i}{ }^{*}=\frac{\sigma_{v}^{2} \mu_{i}+\sigma_{u}^{2} \eta_{i}^{\prime} \varepsilon_{i}}{\sigma_{v}^{2}+\sigma_{u}^{2} \eta_{i}^{\prime} \eta_{i}}
$$

and $\psi$ becomes

$$
\psi_{i}^{*}=\frac{\sigma_{u}^{2} \sigma_{v}^{2}}{\sigma_{v}^{2}+\sigma_{u}^{2} \eta_{i}^{\prime} \eta_{i}} .
$$

The degree of complexity of the model obviously increases with the added generality. The payoff is that the initial assumptions of homogeneity and time invariance are bypassed in the process.

A random effects counterpart to the true fixed effects model would be a 'true random effects' stochastic frontier model,

$$
y_{t t} \quad=\left(\alpha+w_{i}\right)+\mathbf{x}_{i t}{ }^{\prime} \beta+v_{i t}-u_{i t}
$$

The time invariant, random constant term embodies the cross country heterogeneity. The one sided inefficiency component now varies freely across time and country. This form of the model overcomes both of the drawbacks noted earlier. Estimation of this model by simulated maximum likelihood methods is discussed in Greene (2001, 2002a). Measured heterogeneity (income distribution, public contribution to health care financing, etc.) can enter this model through two avenues. Simple cross country heterogeneity may affect the location of the frontier, which would be modeled in the form

$$
w_{i} \quad=\mathbf{f}_{i}^{\prime} \theta+\omega_{i}
$$

This produces a 'hierarchical' or 'multilevel' model. The heterogeneity may also enter the distribution of $u_{i t}$ which can, as before, have mean $\mu_{i}$ or, in principle, even $\mu_{i t}$ with time variation in the covariates. Country specific estimates of inefficiency are computed using the $J L M S$ formulation, though simulation methods are needed to integrate out the unmeasured random effects. 


\section{A Random Parameters Model}

The preceding has suggested various ways to accommodate both cross country heterogeneity and time variation in inefficiency in the stochastic frontier model. The most general of those considered thus far are constructed to accommodate the cross country heterogeneity. Time variation in inefficiency is achieved by removing restrictions on $u_{i t}$ and allowing it to vary unsystematically through time. We now consider two more complete specifications of the stochastic frontier which continue along these lines.

The 'true' random effects model suggested above is a special case of a fully specified random parameters (or hierarchical or multilevel) model,

$$
\begin{aligned}
& y_{i t} \quad=\alpha_{i}+\mathbf{x}_{i t}^{\prime} \boldsymbol{\beta}_{i}+v_{i t}-u_{i t} \\
& \left(\begin{array}{l}
\alpha_{i} \\
\beta_{i}
\end{array}\right)=\left(\begin{array}{l}
\alpha \\
\beta
\end{array}\right)+\left(\begin{array}{l}
\Delta_{\alpha} \\
\Delta_{\beta}
\end{array}\right) \mathbf{h}_{i}+\left(\begin{array}{c}
\omega_{i \alpha} \\
\omega_{i \beta}
\end{array}\right)
\end{aligned}
$$

$$
\begin{array}{ll}
v_{i t} & \sim N\left[0, \sigma_{v}^{2}\right] \\
u_{i t} & =\left|U_{i t}\right| \\
U_{i t} & \sim N\left[\mu_{i}, \sigma_{u}^{2}\right] \\
\mu_{i} & =\mu+\mathbf{h}_{i}^{\prime} \delta_{i} \\
\delta_{i} & =\delta+\Delta_{\delta} \mathbf{h}_{i}+\omega_{i \delta} \\
\omega_{i} & =\left(\omega_{i \alpha}, \omega_{i \beta}^{\prime}, \omega_{i \delta}^{\prime}\right) \sim N[\mathbf{0}, \Omega] .
\end{array}
$$

Estimation of the structural parameters is done by maximum simulated likelihood. As before, the end result is estimates of $u_{i}$ which are computed using the JLMS formulation, from the reduced form, after integrating out the random effects. (The model as stated can be restricted in various ways, for example to place the heterogeneity only in the production function or only in the distribution of the inefficiency.)

\section{Latent Class Models}

The random parameters model allows the heterogeneity to take the form of continuous parameter variation across countries. An alternative, formulation that imposes somewhat more structure is the finite mixture, or latent class model [see Kumbhakar and Orea (2003) and Greene (2003c) for discussion]. The latent class form of the model posits that there are a finite number of structures underlying the data. Each country belongs to one class, though class membership is unknown to the analyst. On first glance, for example, the WHO data might seem naturally to be segregated between OECD and non-OECD countries, or, alternatively, between countries whose main focus in health care priorities is AIDS and other serious epidemics and those more focused 
cancer and other quality of life issues. (Our investigation of these data did not suggest that either of these hypotheses seemed to be valid, however.)

The latent class model would appear as a finite mixture of stochastic frontier models,

$$
\left(y_{i t} \mid \text { class }=j\right) \quad=\alpha_{j}+\mathbf{x}_{i t}{ }^{\prime} \beta_{j}+v_{i t} \mid j-u_{i} j
$$

and a model for the mixing probabilities

$$
\operatorname{Prob}[\text { country } \mathrm{i} \text { is a member of class } \mathrm{j}]=F_{j}\left(\mathbf{h}_{i}, \theta\right), 0 \leq F_{i j} \leq 1 \text {. }
$$

Heterogeneity enters this model through the prior mixing probabilities. As before, it can also enter through the distribution of $u_{i t}$. The latent class model is an alternative to the random parameters model described in the preceding section. With a sufficient number of classes, the finite mixture can provide a good approximation to continuous parameter variation. In practical terms, this model is somewhat less flexible than the random parameters model discussed above. Kumbhakar and Orea (2003) and Greene (2003c) have extended it to the most general variant of the Battese and Coelli formulation of the random effects model. Since this approach is new to the literature, its usefulness as an empirical tool remains to be established.

\subsection{Estimating the Stochastic Frontier Models}

The initial criticisms of the fixed and random effects stochastic models, and to the stochastic frontier model in general, were founded on very narrow forms of the model. With panel data, sufficiently flexible and general forms of the model can be designed that should overcome these limitations and, in the process, produce effective estimates of technical inefficiency. All of these models can be estimated with existing, widely available software, some in Coelli's FRONTIER package (2000) and all of them in LIMDEP [Econometric Software, Inc. (2003).]

As noted by GJJS, the WHO data set, though it is a five year panel, actually contains very little within group variation. As a consequence, many of the model forms noted here are, in fact, not estimable with these data. The results below will present estimates based on a few of the formulations. 


\section{The World Health Organization WHR Data Set}

The data set used in this analysis were used in Evans et al. (2000a,b). ${ }^{13}$ The full data set is a panel of data observed for 191 member countries of the WHO. Observations were also provided for the 8 states of Australia and 32 of Mexico, 12 provinces of Canada, 26 internal jurisdictions of Sweden and 8 internal regions of the United Kingdom for a total of 277 observational units and 840 observations in total. ${ }^{14}$ The panel data are observed for 5 years, 1993 to 1997, though 51 of the 191 countries and all of the aforementioned internal political units are observed in only one year. ${ }^{15}$ The data are more fully described in the World Health Report and in numerous publications that can be obtained from the WHO website.

Two outcome variables were observed,

DALE $\quad=$ Disability Adjusted Life Expectancy. ${ }^{16}$

COMP $=$ composite measure of success in 5 health goals, by year health, health distribution, responsiveness, responsiveness in distribution, fairness in financing. The composite is an equally weighted composite of the five attainment variables. The components of this variable were constructed from survey data gathered by WHO in the respective countries.

Natural logs of both outcome variables were used in the analysis to follow. (All references to these in regression results are based on logs.) GJJS expressed some skepticism about using logs for the DALE variable. In the interest of comparability, we have maintained the forms used by the researchers at WHO in this study.

The first of the outcome variables is the familiar output measure that was analyzed by $H W$, GJJS and Williams in addition to ETML (2000a). The second variable was analyzed in ETML (2000b), but were not analyzed by the other authors mentioned.

Two variables are modeled as the inputs variables to the production process of health care attainment:

HEXP $\quad=$ Health expenditure per capita in 1997 ppp\$,

EDUC $\quad=$ Average years of schooling.

Both input variables entered the production function in log form. The translog model, with squares and the cross product was also considered. A restricted form of this model that has appeared in the earlier studies is discussed below.

13 The assistance of researchers at WHO, especially David Evans and Ajay Tandon is gratefully acknowledged. The data set used here is an expanded version of the data used in ETML $(2000 \mathrm{a}, \mathrm{b})$. The earlier papers did not use the invariant measures, per capita GDP, income distribution, etc.

${ }^{14}$ One of the issues discussed at the meeting mentioned in the introduction was whether it would be useful and appropriate to extend the analysis to the subcountry level units. For purposes of this paper, these data will be left unused. WHO has committed to ongoing study of methods and results of these studies, so these data may yet prove useful.

${ }^{15}$ One country, Algeria, was only observed four times.

${ }^{16}$ A variable DIFF which gives an estimate of the adjustment of DALE for AIDS was given for some countries. This was not used in the analysis. 
Several variables that provide indicators of cross country and timewise heterogeneity were also analyzed:

GINI $=$ Gini coefficient, income inequality,

VOICE $=$ World Bank measure of democratization and freedom of political unit,

GEFF $\quad=$ Measure of government effectiveness, World Bank measure,

TROPICS = Dummy variable for tropical location,

POPDEN = Population density, people per $\mathrm{Km}^{2}$,

PUBFIN = Percentage of health care paid by the government,

GDPC = Per capita GDP in $1997 \mathrm{ppp} \$$,

OECD $\quad=$ Dummy variable for OECD membership ${ }^{17}$.

The population density and per capita GDP variables appear in logs in all model results to follow.

Some of the data series were incomplete and had to be interpolated or otherwise filled in. Details on the data construction are provided in Appendix A. Descriptive statistics for the data used here are given in Table 2. (These are the 1997 values of these variables.)

Table 2: Descriptive Statistics for Variables, 1997 Observations

\begin{tabular}{|l|c|c|c|c|c|c|}
\hline & \multicolumn{2}{|c|}{ Non-OECD } & \multicolumn{2}{c|}{ OECD } & \multicolumn{2}{c|}{ All } \\
\hline & Mean & Std. Dev. & Mean & Std. Dev. & Mean & Std. Dev \\
\hline DALE & 54.32 & 11.73 & 70.27 & 3.01 & 56.83 & 12.29 \\
\hline COMP & 70.30 & 10.96 & 89.42 & 3.97 & 73.30 & 12.34 \\
\hline HEXP & 249.17 & 315.11 & 1498.27 & 762.01 & 445.37 & 616.36 \\
\hline EDUC & 5.44 & 2.38 & 9.04 & 1.53 & 6.00 & 2.62 \\
\hline GINI & 0.399 & 0.0777 & 0.299 & 0.0636 & 0.383 & 0.0836 \\
\hline VOICE & -0.195 & 0.794 & 1.259 & 0.534 & 0.0331 & 0.926 \\
\hline GEFF & -0.312 & 0.643 & 1.166 & 0.625 & -0.0799 & 0.835 \\
\hline TROPICS & 0.596 & 0.492 & 0.0333 & 0.183 & 0.508 & 0.501 \\
\hline POPDEN & 757.9 & 2816.3 & 454.56 & 1006.7 & 710.2 & 2616.5 \\
\hline PUBFIN & 56.89 & 21.14 & 72.89 & 14.10 & 59.40 & 20.99 \\
\hline GDPC & 444.8 & 4717.7 & 18199.07 & 6978.0 & 6609.4 & 7614.8 \\
\hline Sample & \multicolumn{3}{|c|}{161} & \multicolumn{3}{|c|}{30} \\
\hline
\end{tabular}

17 Australia, Austria, Belgium, Canada, Czech Republic, Denmark, Finland, France, Germany, Greece, Hungary, Iceland, Ireland, Italy, Japan, Korea, Luxembourg, Mexico, The Netherlands, New Zealand, Norway, Poland, Portugal, Slovak Republic, Spain, Sweden, Switzerland, Turkey, United Kingdom, United States. 


\section{Technical Inefficiency Estimates from the WHO Data}

\subsection{The Production Function}

A number of researchers have studied health outcomes in a production function framework. Early contributions to this literature are Auster et al. (1969) and Grossman (1972), who analyzed mortality and suggested the approach used by a number of subsequent researchers. Berger and Messer (2002) provide a recent survey of the numerous cross country comparisons. Mortality and life expectancy have provided a focus of this literature. As noted by ETML (2000b), theirs is an innovation in its analysis of a broader measure of health care.

Health expenditure is the most visible input to the process, and public health expenditure is a major component of health care policy. There is tremendous variation in the public share of financing of health expenditure across countries and, as noted by Berger and Messer, across time as well. As can be seen in Table 2, the mean and standard deviation of 59.4 and 21.0 for PUBFIN, respectively suggest a range of variation of at least $20 \%$ to $100 \%$. The interquartile range in our data is $45.4 \%$ to $76.2 \%$; in the raw data, the actual range is from $9 \%$ to $100 \%$. Some specific values for the larger economies include $72 \%$ for Canada, $25 \%$ for China, $92 \%$ for the Czech Republic, $77 \%$ for France, $78 \%$ for Germany, $13 \%$ for India, $57 \%$ for Italy, $82 \%$ for Norway, $78 \%$ for Sweden, $97 \%$ for the United Kingdom and $44 \%$ for the United States. Berger and Messer report comparable figures for some of these countries and note striking changes through time, as well, such as $86 \%$ for the UK in 1993 and an increase from $24 \%$ in 1960 to $41 \%$ in 1985 for the US. It is unclear, however, how or whether at all changes in the public financing of health care will translate to changes in health outcomes. Berger and Messer suggest, for example, that the degree of public financing could lead to either improvement or worsening of the efficiency of health care delivery. As they note, this aspect has not received much attention in the empirical literature. The data and models framed for this study will allow us to examine this issue. They also suggest a range of other factors that might affect health outcomes, such as income, demographic factors, and behavior. Again, the received results on these factors are fairly thin.

A number of researchers have examined the responsiveness of health expenditure to increases in income. Newhouse (1977) reported estimates of the income elasticity of health expenditures in the range of 1.15 to 1.31. Subsequent researchers have examined cross section and pooled time series-cross section data sets with similar results. [See BM (2002) for a survey.] Our own results based on the WHO data for 1997, shown in Table 3 , are consistent, with elasticity estimates of 1.08 for the full sample and 1.23 for the OECD countries. The values in excess of 1.0 suggest that populations value health care as a normal good. How or whether those expenditures translate into health outcomes remains to be established, however. 
Table 3: Income Responsiveness of Health Care Expenditure (Estimated Standard Errors in Parentheses)

\begin{tabular}{|l|ll|ll|ll|l|}
\hline & \multicolumn{2}{|l|}{ Constant } & \multicolumn{2}{l|}{ Income } & \multicolumn{2}{l|}{ Education } & $\boldsymbol{R}^{\mathbf{2}}$ \\
\hline Non-OECD & -3.67 & $(0.251) \star$ & 1.02 & $(0.037) \star$ & 0.275 & $(0.616) \star$ & 0.902 \\
\hline OECD & -5.57 & $(0.747) \star$ & 1.23 & $(0.078) \star$ & 0.347 & $(0.196) \star$ & 0.917 \\
\hline All & -4.14 & $(0.201) \star$ & 1.09 & $(0.031) *$ & 0.268 & $(0.059) \star$ & 0.936 \\
\hline
\end{tabular}

* indicates t statistics larger than 2.0 .

$\mathrm{BM}$ recount a series of cross section studies that have found small and insignificant relationships between income levels and health outcomes. Subsequent analyses of income distribution as an alternative explanation have likewise concluded that the distribution of income adds little explanatory power. Our results of regressions of our two health outcomes, DALE and COMP (in logs) on health care expenditure, education, the Gini measure of income inequality, and the log of per capita income and its square, shown in Table 4, do not agree with these findings. The results suggest that for the poorer, non-OECD countries, there are significant relationships in the expected directions both for per capita income and for the income distribution. The results also suggest that the relationships are stronger for non-OECD countries than for OECD countries. The pattern of the quadratic relationships suggests that the improvement in health outcomes provides greater benefits at lower incomes than at higher ones. For example, for the non-OECD countries, the quadratic relationship suggests that the marginal improvement in $\log \mathrm{COMP}$ becomes zero at income of approximately $\exp (.474 /(2(.050)))=\$ p p p 13,000 .^{18}$ This is roughly the $95^{\text {th }}$ percentile of the income distribution for the 161 nonOECD countries in the sample.

The production relationship suggests, not surprisingly, that health care expenditure should be an input to health outcomes. Authors differ on what else should appear in the function, though education is a common component. Other variables suggested by $B M$ would include health behavior (smoking, eating habits, etc.) demographic composition of the population, other market goods (for which we might use per capita income as a proxy), and country specific terms that should capture other unmeasured heterogeneity. GJJS suggested the difference between per capita GDP and health care expenditure as a measure of this effect. Since our data include only the 1997 per capita GDP, we have used it, rather than the difference, as this variable. There does appear to be something of a consensus in the literature on the direct inputs, health expenditure and education. Evans et al. omitted these from their production function for the practical reason that their fixed effects model could not accommodate time invariant covariates. Our results thus far suggest that a significant amount of explanatory power may have been foregone in the process. Precisely how these covariates should enter the model is another question. Only one of the several panel data models we propose above, the true fixed effects model, is constrained to omit time invariant effects. However, whether such shift factors should enter the production function or the inefficiency distribution is an important question without an obvious answer.

\footnotetext{
${ }^{18}$ This approximation ignores the scaling by $\exp \left(\sigma^{2} / 2\right)$ necessary in the translation from the lognormally distributed variable COMP to the normal variate, $\log \mathrm{COMP}$.
} 
Table 4: Health Care Outcome Regressions ${ }^{\mathrm{a}}$

(Estimated Standard Errors in Parentheses.) ${ }^{b}$

\begin{tabular}{|c|c|c|c|c|c|c|c|c|}
\hline \multirow{5}{*}{ NonOECD } & & Constant & Exp & Educ & Gini & Income & Income $^{2}$ & $R^{2}$ \\
\hline & \multirow[t]{2}{*}{ DALE } & $\begin{array}{l}3.04 \\
(0.176)^{*}\end{array}$ & $\begin{array}{l}0.187 \\
(0.028)^{*}\end{array}$ & $\begin{array}{l}0.017 \\
(0.033)\end{array}$ & $\begin{array}{l}-0.578 \\
(0.148)^{*}\end{array}$ & $\begin{array}{l}0.098 \\
(0.037)^{*}\end{array}$ & & 0.676 \\
\hline & & $\begin{array}{l}-0.712 \\
(0.832)\end{array}$ & $\begin{array}{l}0.130 \\
(0.029)^{*}\end{array}$ & $\begin{array}{l}0.033 \\
(0.313)\end{array}$ & $\begin{array}{l}-0.703 \\
(0.142)^{*}\end{array}$ & $\begin{array}{l}1.046 \\
(0.209)^{*}\end{array}$ & $\begin{array}{l}-0.058 \\
(0.013)^{*}\end{array}$ & 0.715 \\
\hline & \multirow[t]{2}{*}{ COMP } & $\begin{array}{l}3.56 \\
(0.101)^{*}\end{array}$ & $\begin{array}{l}0.100 \\
(0.016)^{*}\end{array}$ & $\begin{array}{l}0.036 \\
(0.191)\end{array}$ & $\begin{array}{c}-0.426 \\
(0.086)^{*}\end{array}$ & $\begin{array}{l}0.064 \\
(0.0214)^{*}\end{array}$ & & 0.769 \\
\hline & & $\begin{array}{l}1.94 \\
(0.495)^{*}\end{array}$ & $\begin{array}{l}0.075 \\
(0.017)^{\star}\end{array}$ & $\begin{array}{l}0.043 \\
(0.019)^{*}\end{array}$ & $\begin{array}{l}-0.481 \\
(0.085)^{*}\end{array}$ & $\begin{array}{l}0.474 \\
(0.124)^{*}\end{array}$ & $\begin{array}{l}-0.025 \\
(0.008)\end{array}$ & 0.784 \\
\hline \multirow{4}{*}{ OECD } & \multirow[t]{2}{*}{ DALE } & $\begin{array}{l}3.82 \\
(1.72)^{*}\end{array}$ & $\begin{array}{l}-0.042 \\
(0.271)\end{array}$ & $\begin{array}{l}0.046 \\
(0.244)\end{array}$ & $\begin{array}{l}-0.102 \\
(0.078)\end{array}$ & $\begin{array}{l}0.0157 \\
(0.0316)\end{array}$ & & 0.725 \\
\hline & & $\begin{array}{l}-0.261 \\
(2.25)\end{array}$ & $\begin{array}{l}-0.041 \\
(0.026)\end{array}$ & $\begin{array}{l}0.036 \\
(0.024)\end{array}$ & $\begin{array}{l}-0.103 \\
(0.074)\end{array}$ & $\begin{array}{l}-0.896 \\
(0.477) \\
\end{array}$ & $\begin{array}{l}-0.046 \\
(0.024) \\
\end{array}$ & 0.760 \\
\hline & \multirow[t]{2}{*}{ COMP } & $\begin{array}{l}3.91 \\
(0.137)^{*}\end{array}$ & $\begin{array}{l}0.035 \\
(0.216)\end{array}$ & $\begin{array}{l}0.341 \\
(0.195)\end{array}$ & $\begin{array}{l}-0.119 \\
(0.621)\end{array}$ & $\begin{array}{l}0.031 \\
(0.025)\end{array}$ & & 0.846 \\
\hline & & $\begin{array}{l}-0.507 \\
(1.69)\end{array}$ & $\begin{array}{l}0.036 \\
(0.195)\end{array}$ & $\begin{array}{l}0.023 \\
(0.180)\end{array}$ & $\begin{array}{l}-0.120 \\
(0.056)^{*}\end{array}$ & $\begin{array}{l}0.967 \\
(0.358)^{*}\end{array}$ & $\begin{array}{l}-0.049 \\
(0.019)^{*}\end{array}$ & 0.880 \\
\hline \multirow{4}{*}{ All } & \multirow[t]{2}{*}{ DALE } & $\begin{array}{l}3.01 \\
(0.162)^{*}\end{array}$ & $\begin{array}{l}0.197 \\
(0.026)^{*}\end{array}$ & $\begin{array}{l}-0.0078 \\
(0.029) \\
\end{array}$ & $\begin{array}{l}-0.397 \\
(0.125)^{*}\end{array}$ & $\begin{array}{l}0.105 \\
(0.034)^{*}\end{array}$ & & 0.714 \\
\hline & & $\begin{array}{l}-0.481 \\
(0.627)\end{array}$ & $\begin{array}{l}0.128 \\
(0.026)^{*}\end{array}$ & $\begin{array}{l}0.031 \\
(0.028)\end{array}$ & $\begin{array}{l}-0.625 \\
(0.122)^{*}\end{array}$ & $\begin{array}{l}0.980 \\
(0.156)^{*}\end{array}$ & $\begin{array}{l}-0.054 \\
(0.009)^{*}\end{array}$ & 0.757 \\
\hline & \multirow[t]{2}{*}{ COMP } & $\begin{array}{l}3.54 \\
(0.093)^{*}\end{array}$ & $\begin{array}{l}0.107 \\
(0.015)^{*}\end{array}$ & $\begin{array}{l}0.024 \\
(0.017) \\
\end{array}$ & $\begin{array}{l}-0.338 \\
(0.072)^{*}\end{array}$ & $\begin{array}{l}0.068 \\
(0.196)\end{array}$ & & 0.823 \\
\hline & & $\begin{array}{l}1.97 \\
(0.371)^{*}\end{array}$ & $\begin{array}{l}0.076 \\
(0.016)\end{array}$ & $\begin{array}{l}0.041 \\
(0.0165)^{*}\end{array}$ & $\begin{array}{l}-0.440 \\
(0.072)^{*}\end{array}$ & $\begin{array}{l}0.462 \\
(0.092)^{*}\end{array}$ & $\begin{array}{l}-0.024 \\
(0.006)^{*}\end{array}$ & 0.840 \\
\hline
\end{tabular}

${ }^{a}$ DALE, COMP, Expenditure, Education, and Per Capita Income are all in logs. Results are all based on the 1997 data.

$\mathrm{b}$ * Indicates $t$ ratios larger than 2.0

The basic production function analyzed here (and in $H W$ ) is of the simple form

$$
\text { Health }_{i t}=f\left(\text { Education }_{i t}, \text { Expenditure }_{i t}\right)+v_{i t}-u_{i t}
$$

Additional influences on health outcomes that appear in the distribution of the inefficiency term are

(25) $\mathbf{h}_{i}=\left[\right.$ GEffi $_{i}$, Voice $_{i}$, Gini $_{i}$, Tropics $_{i}$, PopDen $_{i}$, GDP $_{i}$, PubFin $_{i}$, OECD $\left._{i}\right]$

These will also appear in the production function itself. Finally, in our preferred model, we will allow for time variation with the year specific dummy variables,

$$
\text { t } \quad=\text { year }_{1994}, \text { year }_{1995,} \text {, year } 1996, \text { year }_{1997 .}
$$

The functional form of the production model remains to be determined. ETML specified a translog model,

$$
\begin{aligned}
\text { LogHealth }=\alpha & +\beta_{1} \log E x p+\beta_{2} \log E d u c+\beta_{11}\left[\left(\log ^{2} E d u c\right) / 2\right]+\beta_{22}\left[\left(\log ^{2} E x p\right) / 2\right] \\
& +\beta_{12}[(\log E d u c)(\log E x p)]+v_{i t}-u_{i t},
\end{aligned}
$$


then, in the interest of parsimony, dropped the last two terms. Hollingsworth and Wildman, in the interest of comparability, adopted the same functional form. To maintain continuity of this strand of analysis, we will do likewise. ${ }^{19}$

\subsection{Random and Fixed Effects Estimates of Inefficiency}

Table 5 presents the estimated production functions based on the simplest panel data specifications, ETML's fixed effects model and the Pitt and Lee random effects model. ${ }^{20}$ Neither model has any built in accommodation for cross country heterogeneity. The two estimated models differ substantially, though as shown below, the differences in the estimates of the structural parameters is misleading - the estimated inefficiency terms (estimates of $u_{i}$ ) are nearly identical. The estimated random effects models are consistent with Gravelle et al.'s observation, that there is little within group variation. The variance decomposition is dominated by $u_{i}$; the estimates of $\lambda=\sigma_{u} / \sigma_{v}$ are 25.42 for DALE and 32.16 for COMP. Both of these are quite large by common standards.

Table 5: Estimated Frontier Production Models with Time Invariant Effects (All variables in logarithms. Estimated standard errors in parentheses.)

\begin{tabular}{|c|c|c|c|c|c|c|}
\hline & & Constant & Expenditure & Education & Education $^{2}$ & \\
\hline \multirow[t]{2}{*}{ DALE } & $\begin{array}{l}\text { Fixed } \\
\text { Effects }\end{array}$ & & $\begin{array}{c}0.00884 \\
(0.00305)^{*}\end{array}$ & $\begin{array}{c}0.0629 \\
(0.0363)\end{array}$ & $\begin{array}{c}0.0435 \\
(0.0285)\end{array}$ & $\begin{array}{l}s=0.242 \\
R^{2}=0.999\end{array}$ \\
\hline & $\begin{array}{l}\text { Random } \\
\text { Effects }\end{array}$ & $\begin{array}{l}3.94 \\
(0.0159)^{*}\end{array}$ & $\begin{array}{l}0.0178 \\
(0.00214)^{*}\end{array}$ & $\begin{array}{l}0.106 \\
(0.0175)^{*}\end{array}$ & $\begin{array}{r}0.00672 \\
(0.0145)\end{array}$ & $\begin{array}{l}s_{u}=.2777 \\
s_{V}=.0109\end{array}$ \\
\hline \multirow[t]{2}{*}{ COMP } & $\begin{array}{l}\text { Fixed } \\
\text { Effects }\end{array}$ & & $\begin{array}{c}0.00654 \\
(0.00185)^{*}\end{array}$ & $\begin{array}{c}0.0495 \\
(0.0221)^{*}\end{array}$ & $\begin{array}{c}0.0455 \\
(0.0171)^{*}\end{array}$ & $\begin{array}{l}s=0.172 \\
R^{2}=0.999\end{array}$ \\
\hline & $\begin{array}{l}\text { Random } \\
\text { Effects }\end{array}$ & $\begin{array}{l}4.23 \\
(0.0093)^{*}\end{array}$ & $\begin{array}{l}0.0116 \\
(0.00108)^{*}\end{array}$ & $\begin{array}{c}0.0638 \\
(0.0100)^{*}\end{array}$ & $\begin{array}{c}0.0398 \\
(0.0878)^{*}\end{array}$ & $\begin{array}{l}s_{u}=.2132 \\
s_{v}=.00663\end{array}$ \\
\hline
\end{tabular}

$*$ indicates the $t$ ratio is larger than 2.0 in absolute value. Significant at the $95 \%$ level.

Estimated inefficiencies are computed using the methods discussed earlier. In all cases, to simplify comparisons, we have used the direct estimate of inefficiency, $\hat{u}_{i}$. For the fixed effects estimator, this is simply $\max \left(a_{i}\right)-a_{i}$. The random effects estimator is computed using the Jondrow et al. estimator in (9). Table 6 presents an analysis of these effects. The correspondence between the two sets of estimates, for both health outcomes is striking. The simple correlations between the pairs of estimates is almost 1. The random effects estimators also reproduce the rankings of the fixed effects estimator which, in turn, gives the same results as ETML obtained with their normalized version. (France remains fourth in the DALE results and first in the COMP results, for example.) This degree of correspondence between these two estimators has been observed

\footnotetext{
${ }^{19}$ Based on only the 191 observations for the year 1997, we did obtain $F$ statistics for testing the hypothesis that the two second order terms for expenditure could be omitted from the equation of 9.54 for logDALE and 4.82 for $\log C O M P$. The $99 \%$ critical value from $F[2,185]$ is 4.72 , so both hypotheses would be rejected.

${ }^{20}$ Likelihood functions are not presented with the maximum likelihood estimates in Table 5 or those to follow. Since we are not engaging in any type of specification search, these values would not be useful. Our interest here is in the estimates themselves and in the estimates of technical inefficiency. Fit measures for particular models are tangential to that analysis.
} 
elsewhere. This finding suggests that the impact of the specific distributional assumption of the stochastic frontier model is not so severe as suggested earlier.

Table 6: Analysis of Estimated Technical Inefficiencies.

(Estimated standard errors in parentheses)

\begin{tabular}{|l|c|c|c|c|}
\hline & \multicolumn{2}{|c|}{ DALE } & \multicolumn{2}{c|}{ COMP } \\
\hline & Fixed Effects & Random Effects & Fixed Effects & Random Effects \\
\hline Mean & 0.2287 & 0.2121 & 0.1893 & 0.1772 \\
\hline Standard Dev. & 0.1853 & 0.1793 & 0.1262 & 0.1187 \\
\hline Correlation & \multicolumn{4}{|c|}{0.9984} \\
\hline \multicolumn{5}{|c|}{ Second Step Regression Results } \\
\hline Constant & $1.070(0.139)^{*}$ & $0.9749(0.1377)^{*}$ & $0.7584(0.080)^{*}$ & $0.6826(0.0801)^{*}$ \\
\hline Gini & $0.440(0.1359)^{*}$ & $0.4599(0.1349)^{*}$ & $0.3223(0.079)^{*}$ & $0.3167(0.0784)^{*}$ \\
\hline Voice & $-0.0230(0.0163)$ & $-0.0237(0.0161)$ & $-0.0261(0.009)^{*}$ & $-0.025(0.0094)^{*}$ \\
\hline GEFF & $0.0280(0.0211)$ & $0.0288(0.0209)$ & $0.0065(0.0122)$ & $0.00654(0.012)$ \\
\hline LogPopDensity & $-0.0095(-.0054)$ & $-0.0095(0.0054)$ & $-0.0061(0.0031)$ & $-0.0059(0.0031)$ \\
\hline LogIncome & $-0.121(0.0146)^{*}$ & $-0.111(0.0145)^{*}$ & $-0.0806(0.0085)$ & $-0.073(0.0085)^{*}$ \\
\hline Tropics & $0.0506(0.0230)^{*}$ & $0.0515(0.0228)$ & $0.0136(0.0133)$ & $0.0121(0.0132)$ \\
\hline Public Finance & $-0.00024(0.001)$ & $-0.0003(0.0005)$ & $-0.0002(0.0003)$ & $-0.0002(0.0003)$ \\
\hline OECD & $0.1014(0.0365)^{*}$ & $0.0989(0.0363)$ & $0.0538(0.0212)$ & $0.0522(0.0211)^{*}$ \\
\hline$R^{2}$ & 0.5533 & 0.5299 & 0.6774 & 0.6371 \\
\hline
\end{tabular}

* indicates t ratios greater than 2.0 in absolute value. Statistical significance at $95 \%$ level.

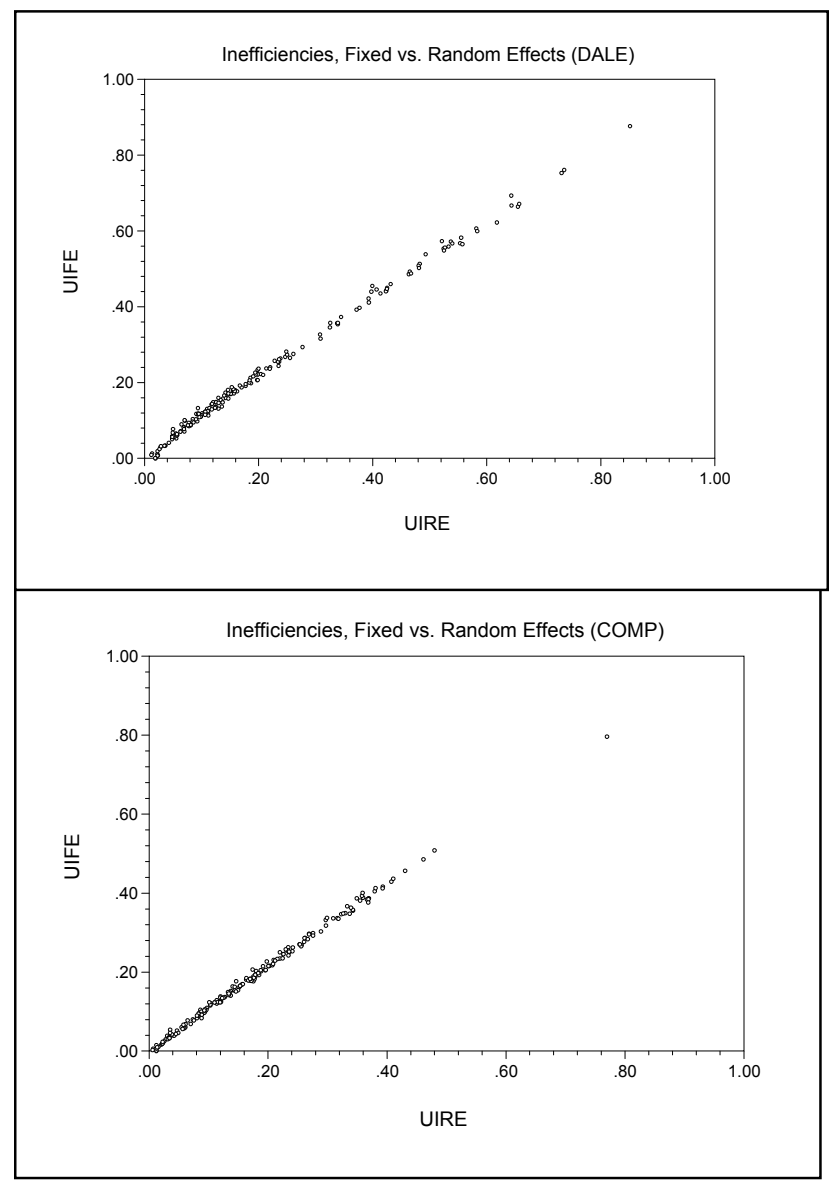

Figure 3: Estimated Fixed and Random Effects Inefficiencies 
The lower panel of Table 6 presents a second step analysis of the estimated inefficiencies from the two models. They suggest that income and the distribution of income are both significant in explaining variation in efficiency. Since $u_{i}$ is in proportional terms, the absolute magnitudes of the coefficients give the proportional impacts. It appears that the most important determinant is the distribution of income, with larger values of the gini coefficient (less equal income distribution) having a major negative impact on health outcomes however measured. (Increases in $u_{i}$ imply lower efficiency.) The second largest determinant is per capita income, which works in the expected direction - higher income is associated with more efficient delivery of health care and achievement of higher life expectancy. (These results are not interpretable as direct impacts on the health outcomes.) Surprisingly, OECD status is associated with less efficient production. Note, though that per capita income is already in the equation, so whatever effect is at work in this persistent result is net of the impact of per capita income.

\subsection{Incorporating Measured Heterogeneity in the Estimates of Inefficiency}

The second step analysis of estimated inefficiencies such as that shown in Table 6 is a common exercise. In principle, if there are significant determinants of $u_{i}$ in the observed information set, then they should appear in the model at the outset, and it may well be that estimates obtained without them suffer from the usual sorts of left out variable biases that are widely acknowledged in regression analysis. [Schmidt and Wang (2002) discuss this issue at length with respect to stochastic frontier analysis.] ETML's fixed effects estimator provides no method of accommodating time invariant indicators of heterogeneity in the model, but most of the others discussed to. Table 7 presents estimates of a random effects truncated normal stochastic frontier in which the time invariant covariates appear in the underlying mean of $U_{i}$. This is the heterogeneous form, with $\mathrm{E}\left[U_{i}\right]=\mu_{i}=\mathbf{z}_{i}^{\prime} \delta$. The pattern in these results is similar to the preceding outcome. Once again, per capita income and the distribution of income appear to be significant determinants of the mean level of inefficiency, again in the expected direction. The inefficiency in the life expectancy equation is also significantly affected by tropical location.

The incorporation of cross country heterogeneity in the model has also produced the expected result with respect to the variation in inefficiency. In Table 2, in the simple random effects model, the standard deviation of the underlying distribution of $U_{i}, \sigma_{u}$, is estimated as 0.2777 and 0.2132 for DALE and COMP, respectively. In the expanded model in Table 7, the counterparts are 0.1567 and 0.07669. A large proportion of the variation in 'inefficiency' appears to be explainable as heterogeneity in the mean, instead. The estimates of the residual variation, $\sigma_{v}$, are identical in the two formulations.

We have included in Table 7 a comparison to the fixed effects estimates produced by ETML. As before, the results are strikingly similar, though noticeable differences can be seen as well. Figures 4 and 5 show the correspondence graphically. In fact, the statistical results in Table 7 do not reveal some rather large adjustments. For many countries, this expansion of the model appears to be fine tuning, but for a large number of others, quite substantial differences emerge. Table 8 shows the effect of the respecified model on the ranks of the top ten countries in the original fixed effects form. 
Table 7: Estimated Heterogeneous Truncated Normal Stochastic Frontiers (Estimated Standard Errors in Parentheses)

\begin{tabular}{|c|c|c|c|c|c|}
\hline & & \multicolumn{2}{|c|}{ DALE } & \multicolumn{2}{|l|}{ COMP } \\
\hline & & Truncation & Batt./Coelli & Truncation & Batt./Coelli \\
\hline \multirow{4}{*}{$\begin{array}{l}\text { Production } \\
\text { Function }\end{array}$} & Constant & $\begin{array}{l}3.96 \\
(0.0196)^{*}\end{array}$ & $\begin{array}{l}3.87 \\
(0.0156)^{*}\end{array}$ & $\begin{array}{l}4.27 \\
(0.0117)^{*}\end{array}$ & $\begin{array}{l}4.29 \\
(0.0188)^{*}\end{array}$ \\
\hline & $\operatorname{Exp}$ & $\begin{array}{l}0.0162 \\
(0.0023)^{*}\end{array}$ & $\begin{array}{l}0.0169 \\
(0.0021)^{*}\end{array}$ & $\begin{array}{l}0.00950 \\
(0.00129)^{*}\end{array}$ & $\begin{array}{l}0.0091 \\
(0.0013)^{*}\end{array}$ \\
\hline & Educ & $\begin{array}{l}0.1238 \\
(0.0166)^{*}\end{array}$ & $\begin{array}{l}0.2037 \\
(0.0179)^{*}\end{array}$ & $\begin{array}{l}0.0867 \\
(0.00987)^{*}\end{array}$ & $\begin{array}{l}0.0790 \\
(0.0134)^{*}\end{array}$ \\
\hline & Educ $^{2}$ & $\begin{array}{l}-0.0204 \\
(0.0120)\end{array}$ & $\begin{array}{l}-0.0667 \\
(0.0118)^{*}\end{array}$ & $\begin{array}{l}-0.000827 \\
(0.00856)\end{array}$ & $\begin{array}{l}0.0019 \\
(0.0089) \\
\end{array}$ \\
\hline \multirow{9}{*}{$\begin{array}{l}\text { Mean } \\
\text { Inefficiency }\end{array}$} & Constant & $\begin{array}{l}8.65 \\
(1.88)^{*}\end{array}$ & $\begin{array}{l}1.20 \\
(0.310)^{*}\end{array}$ & $\begin{array}{l}10.568 \\
(1,50)^{*}\end{array}$ & $\begin{array}{l}0.829 \\
(0.115)^{*}\end{array}$ \\
\hline & Gini & $\begin{array}{l}6.06 \\
(1.46)^{*}\end{array}$ & $\begin{array}{l}0.985 \\
(0.239)^{*}\end{array}$ & $\begin{array}{l}6.58 \\
(1.13)^{*}\end{array}$ & $\begin{array}{l}0.508 \\
(0.0804)^{*}\end{array}$ \\
\hline & Voice & $\begin{array}{l}-0.2312 \\
(0.207)\end{array}$ & $\begin{array}{l}-0.366 \\
(0.0350)\end{array}$ & $\begin{array}{l}-0.448 \\
(0.146)^{*}\end{array}$ & $\begin{array}{l}-0.0349 \\
(0.0117)^{*}\end{array}$ \\
\hline & GEFF & $\begin{array}{l}0.00534 \\
(0.307)\end{array}$ & $\begin{array}{l}-0.0016 \\
(0.0514)\end{array}$ & $\begin{array}{l}-0.0722 \\
(0.183) \\
\end{array}$ & $\begin{array}{l}-0.00513 \\
(0.0145) \\
\end{array}$ \\
\hline & Pop. Density & $\begin{array}{l}-0.0767 \\
(0.0577)\end{array}$ & $\begin{array}{l}-0.0118 \\
(0.0095)\end{array}$ & $\begin{array}{l}-0.0829 \\
(0.0474)\end{array}$ & $\begin{array}{l}-0.00643 \\
(0.00371)\end{array}$ \\
\hline & $\begin{array}{l}\text { GDP Per } \\
\text { capita }\end{array}$ & $\begin{array}{l}-1.25 \\
(0.207)^{*}\end{array}$ & $\begin{array}{l}-0.182 \\
(0.0378)^{*}\end{array}$ & $\begin{array}{l}-1.27 \\
(0.153)^{*}\end{array}$ & $\begin{array}{l}-0.0994 \\
(0.0121)^{*}\end{array}$ \\
\hline & Tropics & $\begin{array}{l}0.6402 \\
(0.280)^{*}\end{array}$ & $\begin{array}{l}0.0997 \\
(0.049)^{*}\end{array}$ & $\begin{array}{l}0.287 \\
(0.202)\end{array}$ & $\begin{array}{l}0.0229 \\
(0.0158)\end{array}$ \\
\hline & $\begin{array}{l}\text { Public } \\
\text { Finance }\end{array}$ & $\begin{array}{l}-0.00253 \\
(0.00656)\end{array}$ & $\begin{array}{l}-0.0004 \\
(0.0011)\end{array}$ & $\begin{array}{l}-0.00497 \\
(0.00519)\end{array}$ & $\begin{array}{l}-0.0004 \\
(0.0004)\end{array}$ \\
\hline & OECD & $\begin{array}{l}-0.0965 \\
(1.032)\end{array}$ & $\begin{array}{l}-0.0480 \\
(0.177)\end{array}$ & $\begin{array}{l}-0.272 \\
(0.696)\end{array}$ & $\begin{array}{l}-0.0207 \\
(0.0537)\end{array}$ \\
\hline \multirow{7}{*}{$\begin{array}{l}\text { Distributions of } \\
u \text { and } v\end{array}$} & $\sigma_{u}$ & 0.1567 & 0.1564 & 0.07669 & 0.07681 \\
\hline & $\sigma_{v}$ & 0.01092 & 0.01065 & 0.00664 & 0.00664 \\
\hline & $\lambda$ & 14.349 & 14.685 & 11.542 & 11.566 \\
\hline & Year 1994 & & $\begin{array}{l}0.0081 \\
(0.026)^{*}\end{array}$ & & \begin{tabular}{|l|}
-.000051 \\
$(0.018)$
\end{tabular} \\
\hline & Year 1995 & & $\begin{array}{l}0.0148 \\
(0.0208)\end{array}$ & & \begin{tabular}{|l|}
-.00089 \\
$(0.0159)$
\end{tabular} \\
\hline & Year 1996 & & $\begin{array}{l}0.0227 \\
(0.0174)\end{array}$ & & \begin{tabular}{|l}
-0.0019 \\
$(0.0165)$
\end{tabular} \\
\hline & Year 1997 & & $\begin{array}{l}0.0301 \\
(0.0129)^{*}\end{array}$ & & \begin{tabular}{|l|}
-0.00323 \\
$(0.0109)$
\end{tabular} \\
\hline \multirow{4}{*}{$\begin{array}{l}\text { Estimated } \\
\text { Inefficiency (In } \\
\text { Comparison to } \\
\text { Fixed Effects } \\
\text { Estimates) }\end{array}$} & Correlation & 0.884 & 0.993 & 0.891 & 0.993 \\
\hline & Rnk Corr. & \begin{tabular}{|l|}
0.891 \\
\end{tabular} & $\mathrm{X}$ & 0.895 & $X$ \\
\hline & Mean & $0.196(0.229)$ & $0.195(0.229)$ & $0.160(0.189)$ & $0.178(0.189)$ \\
\hline & Std. Deviation & $0.189(0.185)$ & $0.181(0.185)$ & $0.149(0.126)$ & $0.128(0.126)$ \\
\hline
\end{tabular}

* indicates t ratios greater than 2.0 in absolute value. Statistical significance at $95 \%$ level. 
Table 8: Selected Country Ranks Based on the Random Effects Model

\begin{tabular}{|l|l|c|l|c|}
\hline & \multicolumn{2}{|c|}{ DALE } & \multicolumn{2}{c|}{ COMP } \\
\hline Rank in FE & Country & New Rank & Country & New Rank \\
\hline $\mathbf{1}$ & Malta & 3 & France & 1 \\
\hline $\mathbf{2}$ & Oman & 7 & Italy & 2 \\
\hline $\mathbf{3}$ & Italy & 4 & San Marino & 72 \\
\hline $\mathbf{4}$ & France & 5 & Andorra & 74 \\
\hline $\mathbf{5}$ & San Marino & 40 & Malta & 8 \\
\hline $\mathbf{6}$ & Spain & 2 & Singapore & 7 \\
\hline $\mathbf{7}$ & Andorra & 42 & Spain & 4 \\
\hline $\mathbf{8}$ & Jamaica & 8 & Oman & 25 \\
\hline $\mathbf{9}$ & Japan & 1 & Austria & 6 \\
\hline $\mathbf{1 0}$ & Greece & 6 & Japan & 3 \\
\hline
\end{tabular}

The second set of estimates in each grouping in Table 7 are for Battese and Coelli's extension of the random effects model. This form of the model incorporates some time variation in the inefficiency; the generic specification is

$$
U_{i t} \quad=g\left(\mathbf{z}_{i}, \mathbf{t}, \theta\right)\left|U_{i}\right|
$$

This is a hybrid. The time variation is systematic. The underlying random component of the inefficiency remains time invariant. The effect of this on the overall nature of the inefficiency is a bit ambiguous. We have adopted an extension of Kumbhakar and Orea's (2003) form, with separate time effects (dummy variables) and a linear function of the country specific effects. Thus, this model includes measured country heterogeneity both directly in the production function and in the inefficiency distribution. The results in Table 7 suggest that both production and the efficiency of production are significantly affected by both the distribution of income and the level of per capita income. This persistent result has been hinted at in previous analysis. We do find considerable evidence of the result in our estimates. Figure 6 plots the estimates of $u_{i}$ for this model. As before, it produces quite similar results to the fixed effects estimator. 


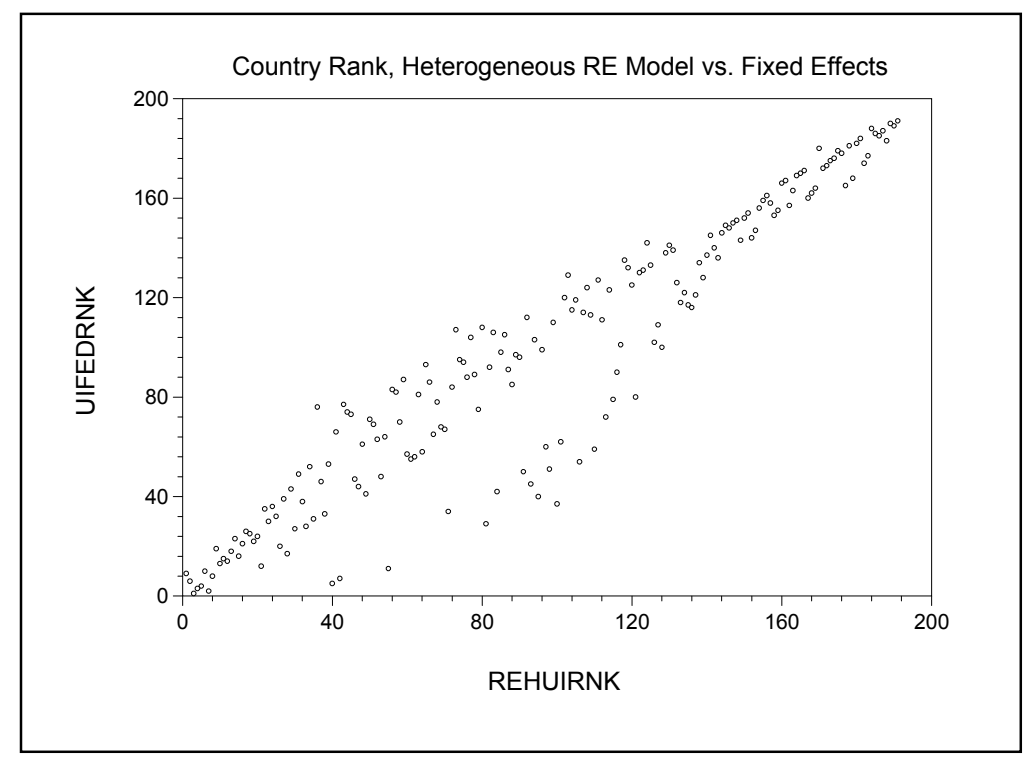

Figure 4a: Ranks Based on Fixed Effects and Random Effects Models

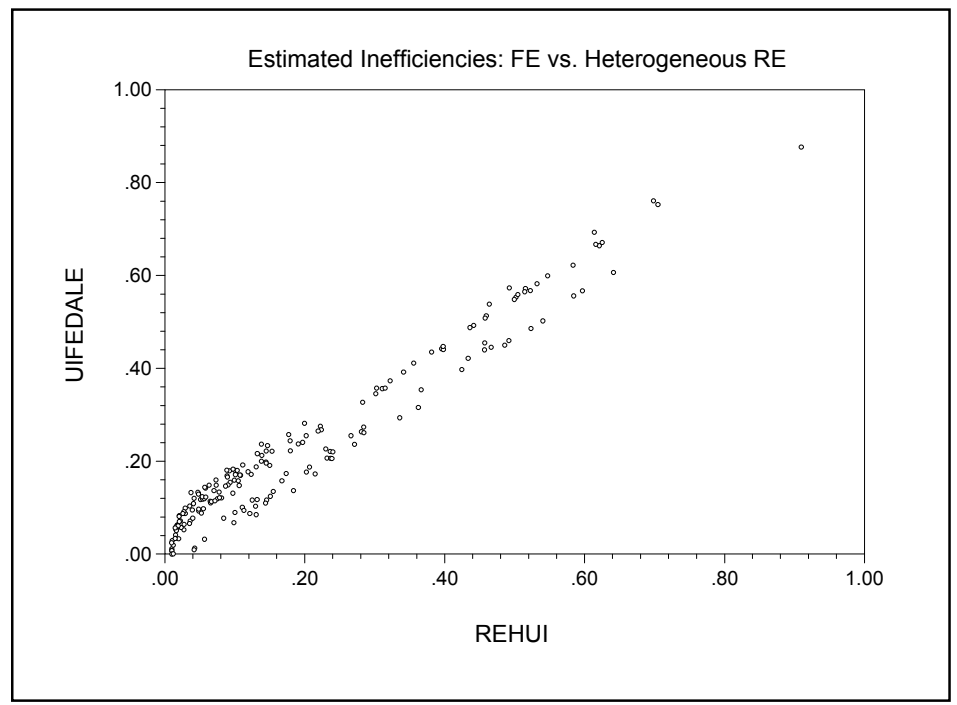

Figure 4b: Efficiencies Based on Fixed Effects and Random Effects Models

Figure 4: Comparison of Heterogeneous Random Effects to Fixed Effects Estimates, DALE 


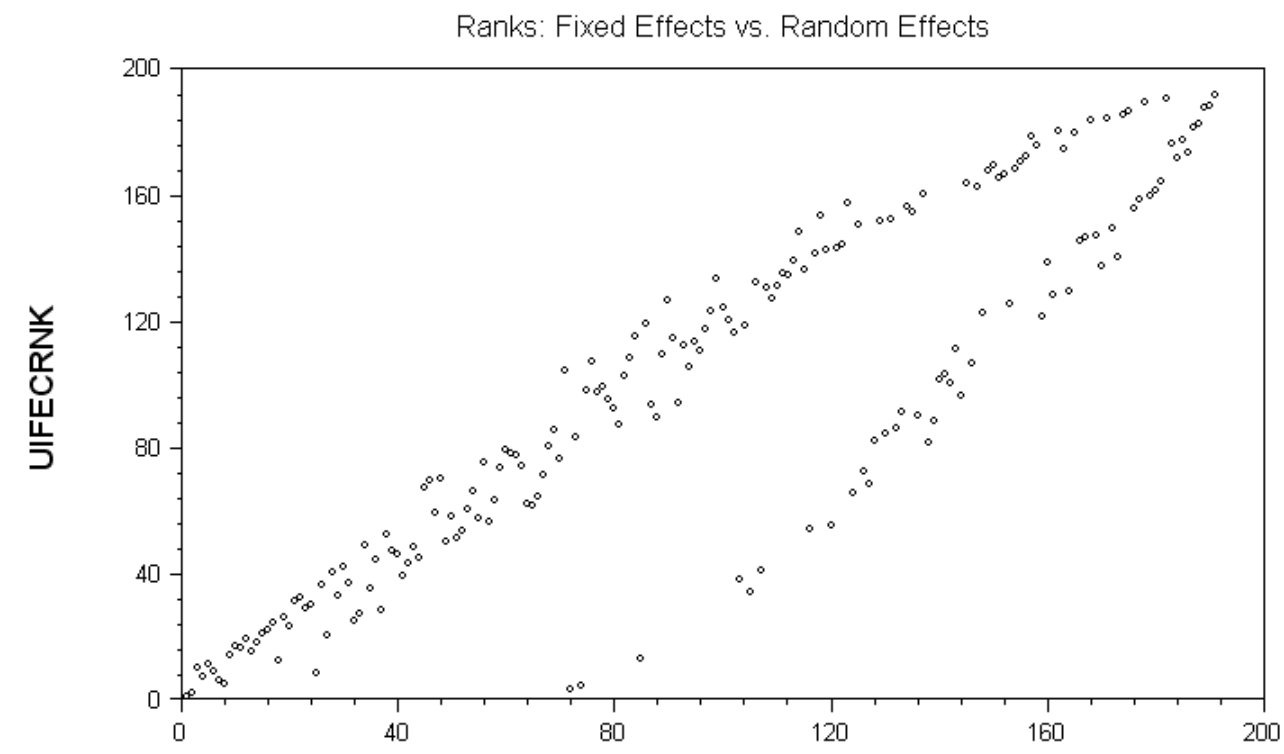

Figure 5a: Ranks Based on Fixed Effects and Random Effects Models

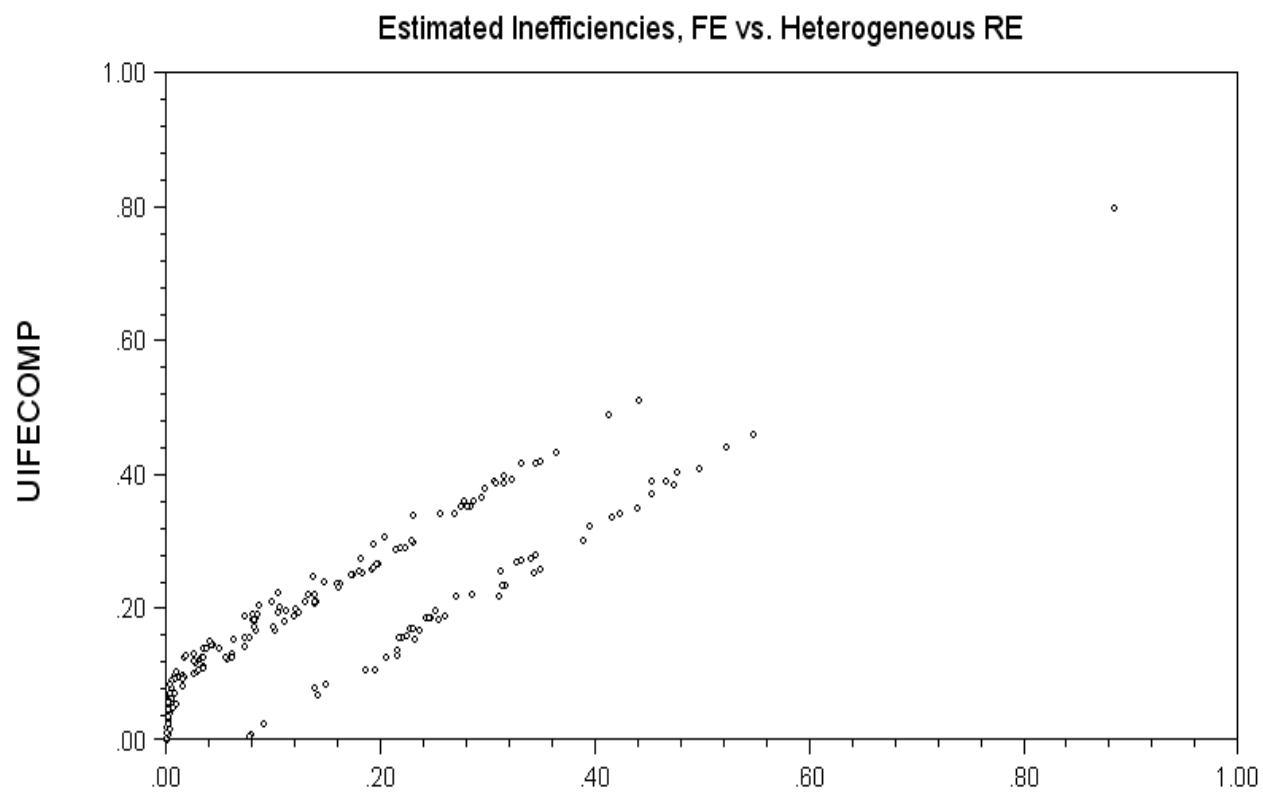

Figure 5b: Efficiencies Based on Fixed Effects and Random Effects Models

Figure 5: Comparison of Heterogeneous Random Effects to Fixed Effects Estimates, COMP 
Fixed Effects vs. Battese Coelli Random Effects: DALE

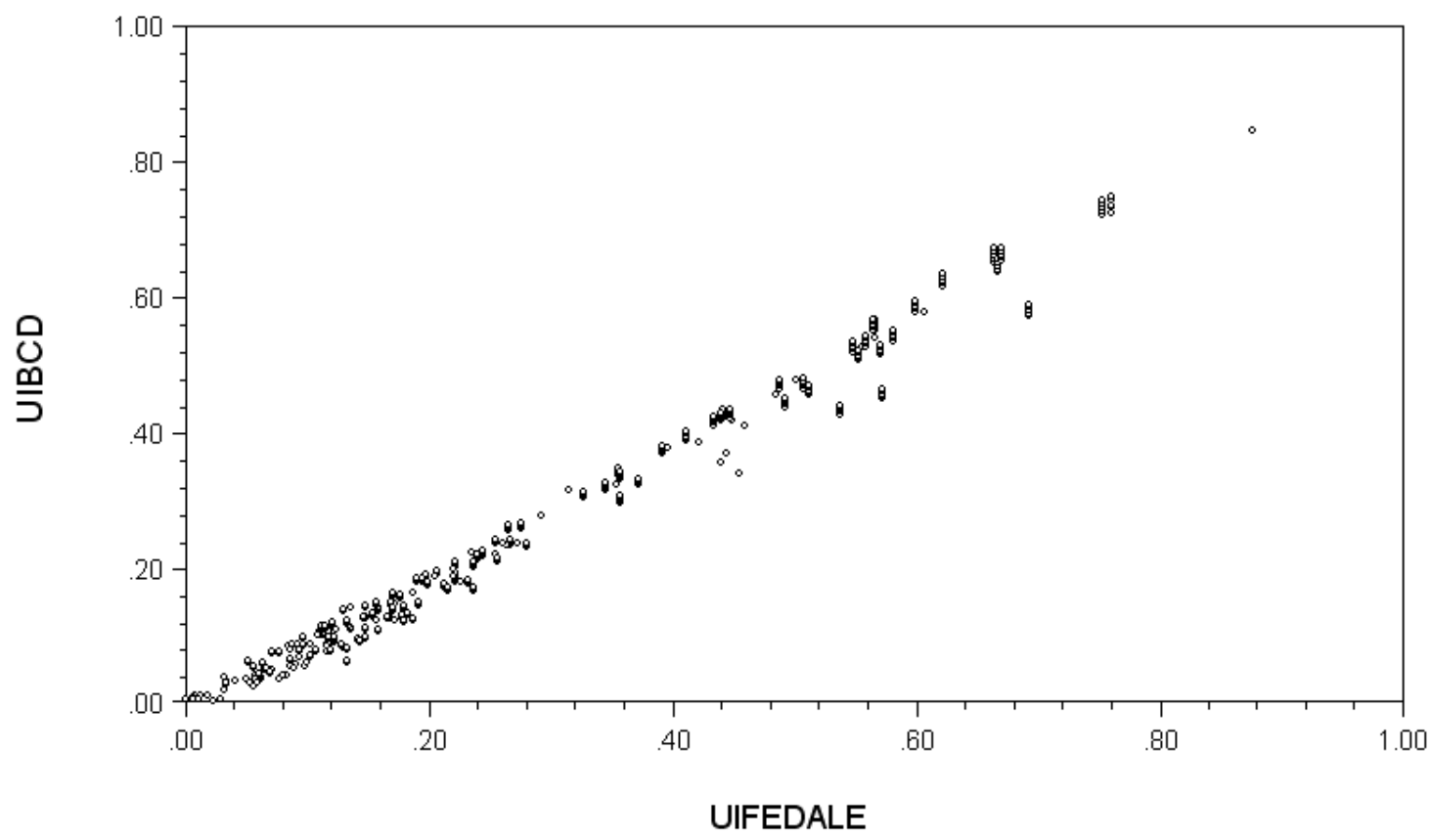

Figure 6a: Fixed Effects and Battese-Coelli Estimates, DALE

Fixed Effects vs. Battese Coelli Random Effects: COMP

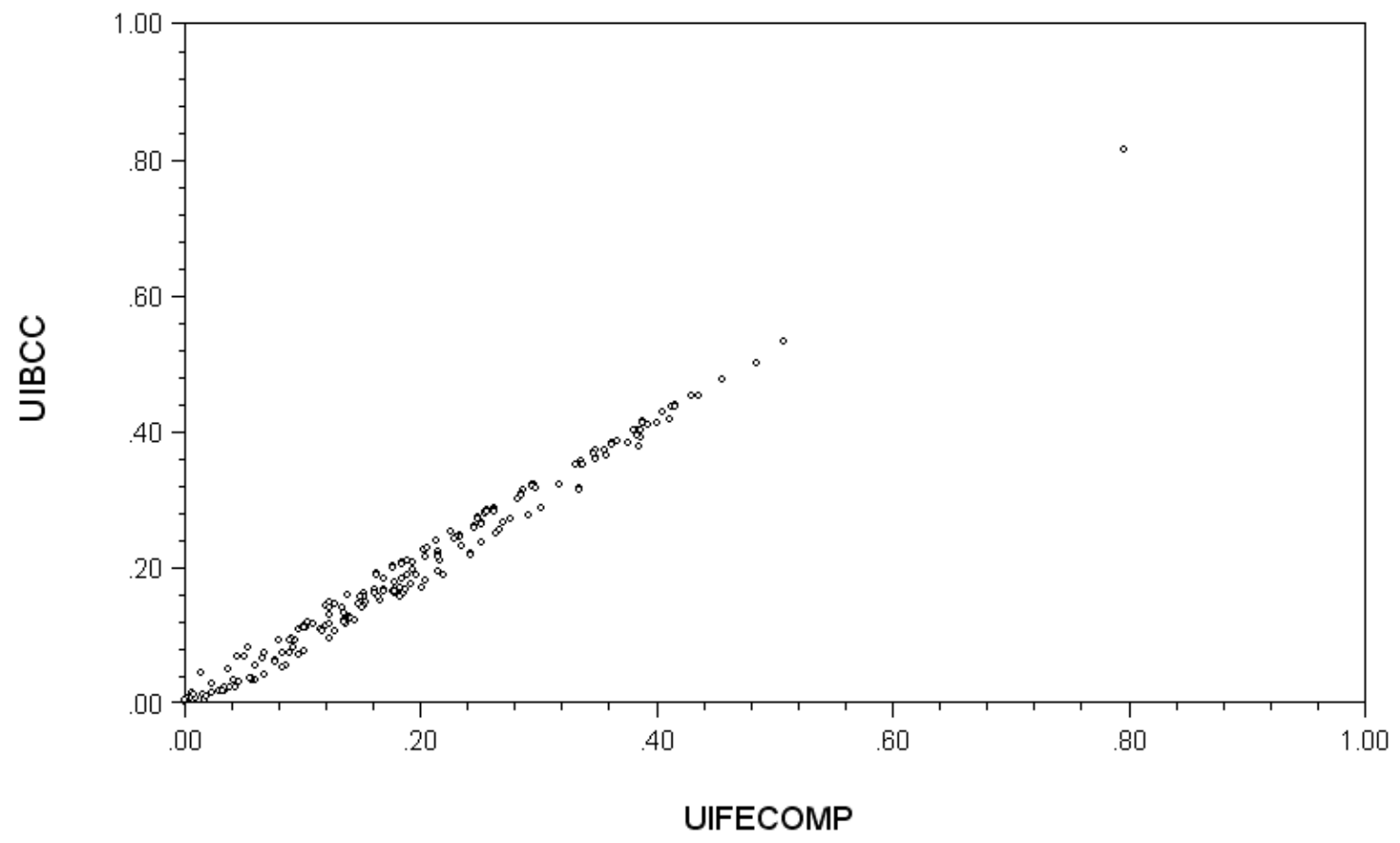

Figure 6b: Fixed Effects and Battese-Coelli Estimates, COMP 


\subsection{Incorporating Measured Heterogeneity in the Production Function}

A primary motivation for the model extensions presented here is the possibility that the models with time invariant inefficiencies (random and fixed effects) might be forcing other unmeasured heterogeneity unrelated to technical efficiency into the estimates of $u_{i}$. The extensions in Sections 4.2 and 4.3 move some indicators of heterogeneity into the distribution of $u_{i}$, but retain the feature that other country characteristics are omitted from the model. We can accommodate this to some degree by retaining the random effects formulation, but building the cross country variation into both the production function and the distribution of inefficiency. The resulting structure is quite general;

$$
\begin{array}{ll}
y_{i t} & =\alpha+\mathbf{z}_{i}^{\prime} \gamma+\mathbf{t}^{\prime} \theta+\mathbf{x}_{i t}^{\prime} \beta+v_{i t}-u_{i} \\
u_{i} & =\left|U_{i}\right| \\
U_{i} & \sim \mathrm{N}\left[\mu_{i}, \sigma_{u}{ }^{2}\right], \mu_{i}=\mathbf{z}_{i}{ }^{\prime} \delta
\end{array}
$$

This extends the original ETML model in two ways, neither of which can be accommodated in the fixed effects formulation. We have also added time variation to the shift factors in the production. (The model is inestimable with these included in the mean of $U_{i}$.)

Table 9 presents parameter estimates for this model. (In the interest of brevity, at this point, we have omitted the estimated standard errors. The patterns of statistical significance are indicated in the results as in the preceding tables.) In terms of its impacts in the model, we now see that per capita income remains an important determinant both of the level of and efficiency of production. But, the distribution of income (Gini) appears to be an important determinant only of the efficiency of production. In view of our previously estimated models, this appears to uncover an important specification problem. In models less general than this one, it does appear that significant influences on efficiency, such as Gini, could be misplaced, and appear to be significant at points where they in fact might not be. Figures $7 \mathrm{a}$ and $7 \mathrm{~b}$ display the estimates of $u_{i}$ from this model, once again in comparison to the initial estimates in ETML. We have segregated the estimates by OECD and non-OECD countries in the figures and in the descriptive statistics in Table 9. This partition of the sample reveals a major aspect to all of the results. In the figures, the OECD countries are packed tightly in the lower left corner of the plots. From the descriptive statistics, as borne out by the figures, we now see that nearly all of the variation in the estimated inefficiencies in both ETML's fixed effects estimates, and these, our final proposed alternatives, is attributable to the non-OECD countries in the sample.

It can be seen in the figures that this model brings some rather large changes in the results. To explore this further, we have plotted the country ranks for the DALE estimates in Figure 8. (The figure for COMP is similar.) The results have changed considerably. Table 10 lists the to 25 countries from the original fixed effects model, and their ranks produced by this more general model. 
Table 9: Estimated Heterogeneous Truncated Normal Stochastic Frontiers

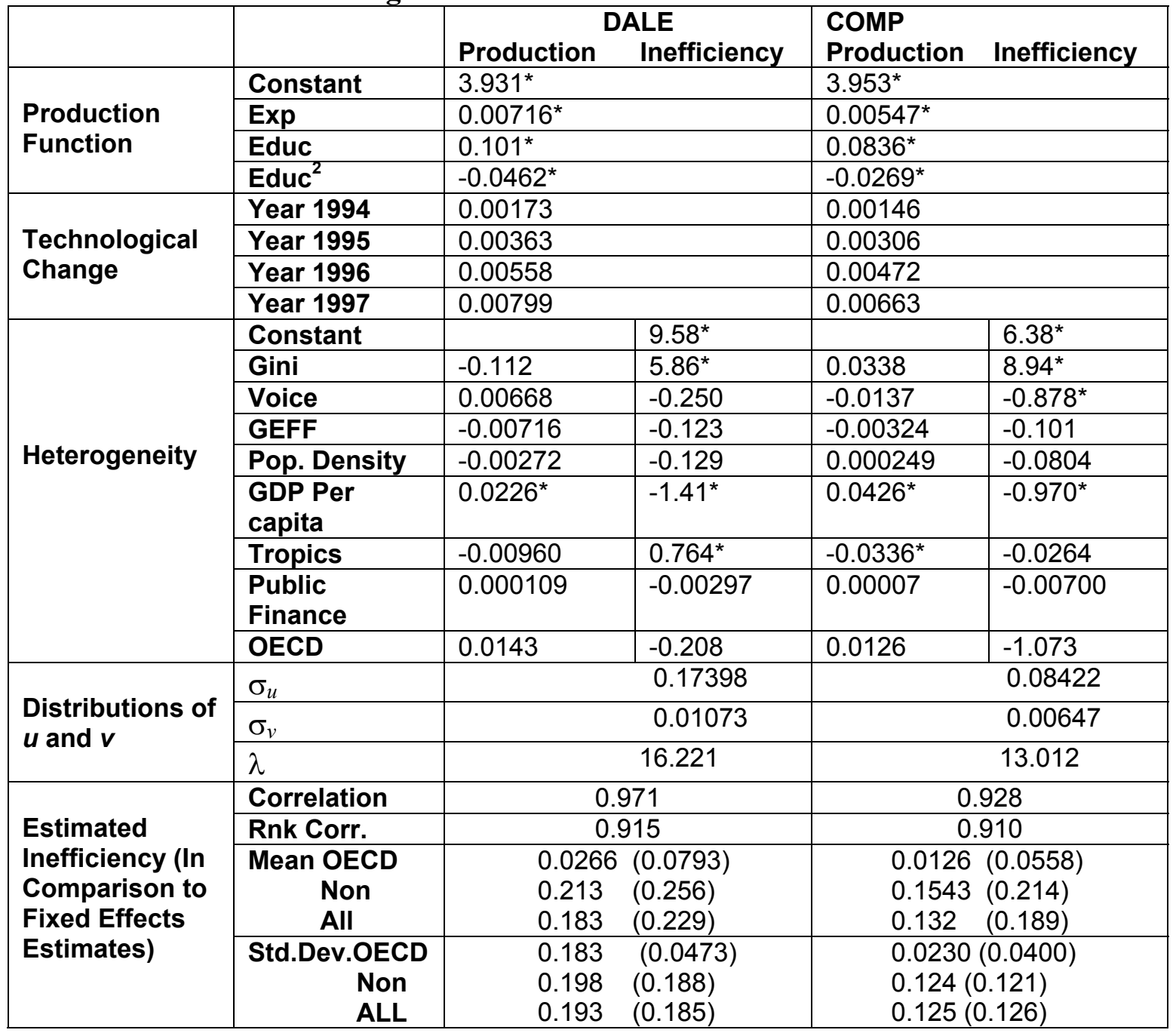

* indicates $t$ ratios greater than 2.0 in absolute value. Statistical significance at $95 \%$ level. 
Fixed Effects vs. Heterogeneous Random Effects

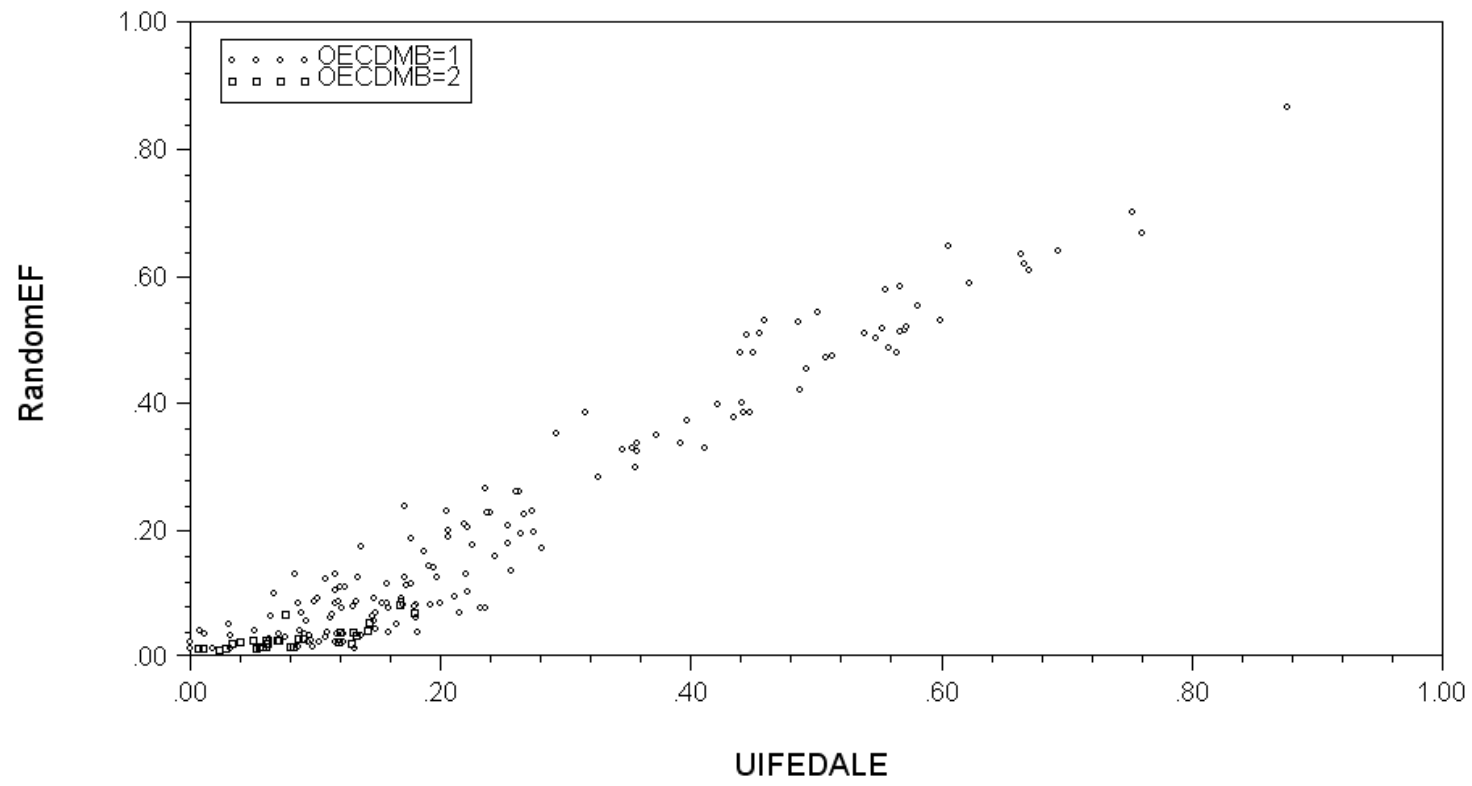

Figure 7a: Fixed Effects and Heterogeneous Random Effects Estimates, DALE

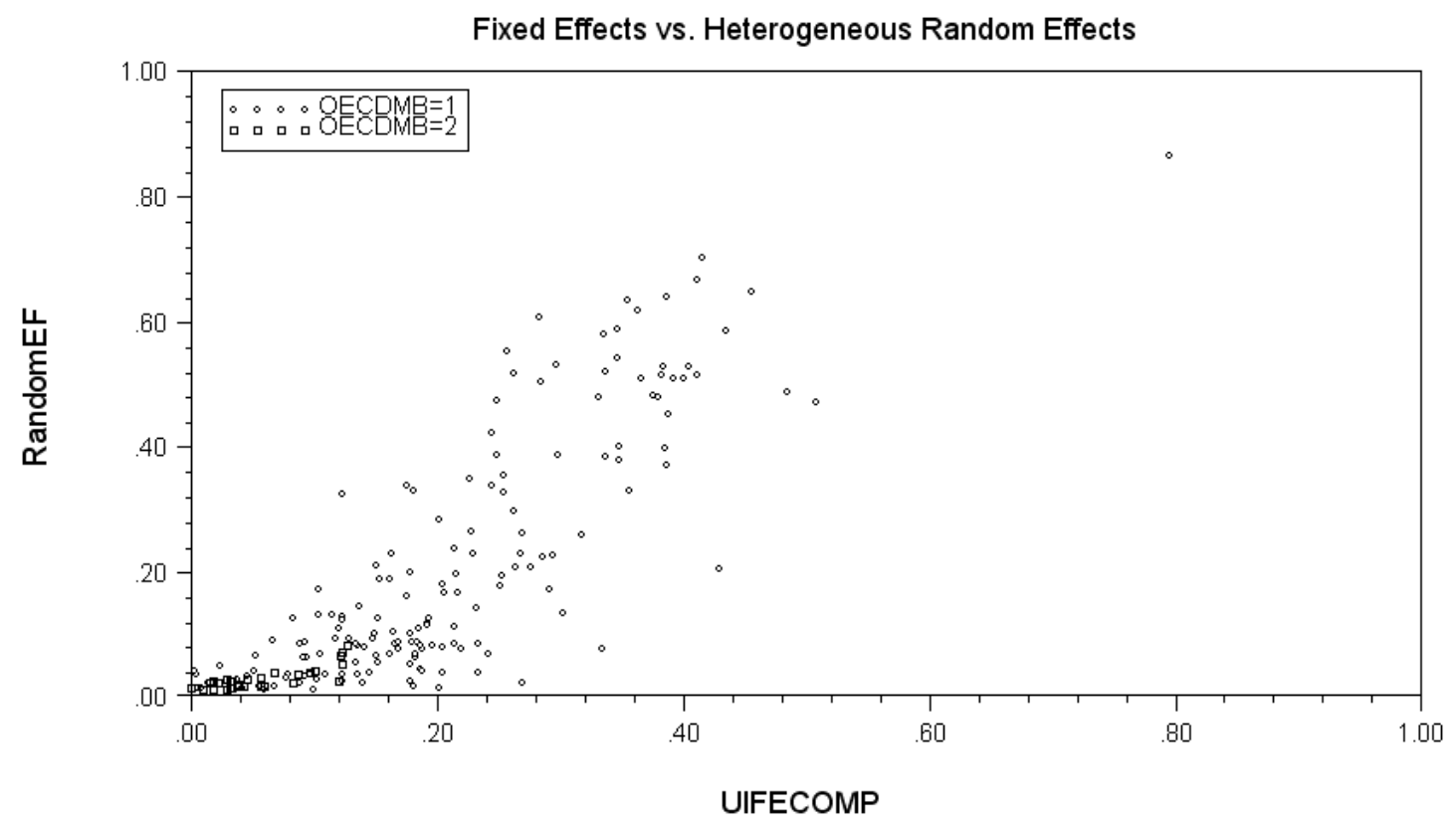

Figure 7b: Fixed Effects and Heterogeneous Random Effects Estimates, COMP 


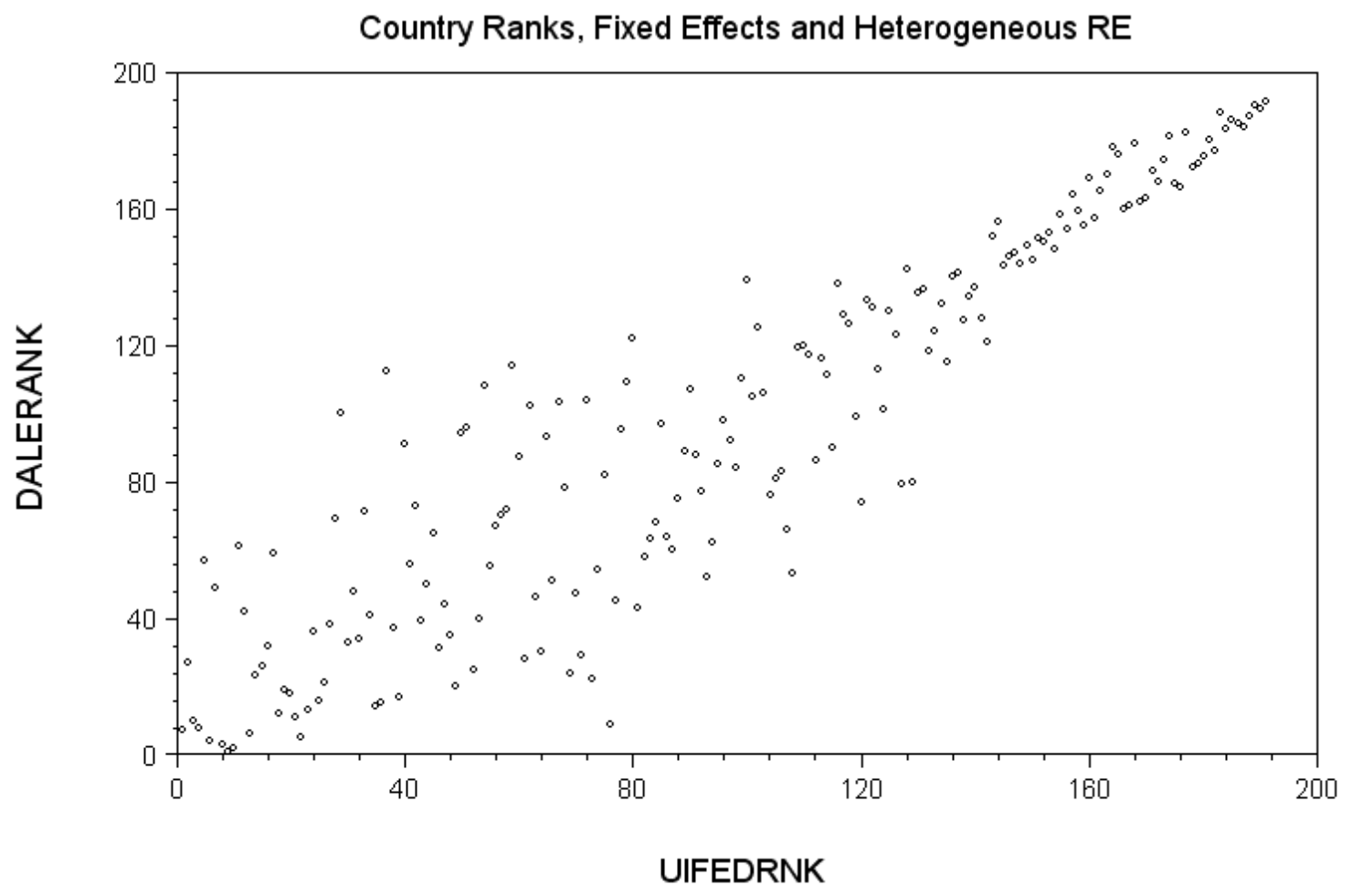

Figure 8: Country Ranks: Fixed Effects and Heterogeneous Random Effects, DALE

\subsection{Alternative Estimates of Technical Efficiency}

More detailed and elaborate models are discussed in Section 5.6. But, for reasons discussed below, these methods appear to be unsuitable for this data set. The model in Section 5.4 is our preferred specification. As a benchmark against alternative specifications, the results given there compare measures from these models to the fixed effects model based on otherwise the same specification. Save for the normalizations discussed earlier, however, these are comparable to Evans et al.'s results. The results shown in the preceding section are our alternative estimates. The direct comparison to Evans et al's estimates is presented in Table 11. The values in the table are based on their efficiency measure. The comparison to Evans' total effectiveness measure would be

$$
\widehat{T E}_{i}=\exp \left(-\hat{u}_{i}\right)
$$

As before, most of the variation in the measured values comes from the non-OECD countries. The correlation of the ranks is compute using

$$
\text { Rank Correlation }=1-\frac{6 \sum_{i=1}^{191}\left(\operatorname{Rank}_{E T M L, i}-\operatorname{Rank}_{i}\right)^{2}}{191\left(191^{2}-1\right)}
$$


Table 10: Country Ranks for the top 25 Countries in ETML Sample

\begin{tabular}{|l|l|r|l|c|}
\hline & \multicolumn{2}{|c|}{ DALE } & \multicolumn{2}{c|}{ COMP } \\
\hline Rank & Country & New Rank & Country & New Rank \\
\hline $\mathbf{1}$ & Malta & 7 & France & 15 \\
\hline $\mathbf{2}$ & Oman & 27 & Italy & 11 \\
\hline $\mathbf{4}$ & Italy & 10 & San Marino & 59 \\
\hline $\mathbf{5}$ & France & 8 & Andorra & 58 \\
\hline $\mathbf{6}$ & San Marino & 4 & Malta & 6 \\
\hline $\mathbf{7}$ & Andorra & 49 & Singapore & 8 \\
\hline $\mathbf{8}$ & Jamaica & 3 & Oman & 2 \\
\hline $\mathbf{9}$ & Japan & 1 & Austria & 41 \\
\hline $\mathbf{1 0}$ & Greece & 2 & Japan & 17 \\
\hline $\mathbf{1 1}$ & Monaco & 61 & Norway & 3 \\
\hline $\mathbf{1 2}$ & Saudi Arabia & 42 & Portugal & 10 \\
\hline $\mathbf{1 3}$ & Singapore & 6 & Monaco & 32 \\
\hline $\mathbf{1 4}$ & Portugal & 23 & Greece & 69 \\
\hline $\mathbf{1 5}$ & Austria & 26 & Iceland & 1 \\
\hline $\mathbf{1 6}$ & Norway & 32 & Netherlands & 21 \\
\hline $\mathbf{1 7}$ & United Arab Emir. & 59 & Luxembourg & 3 \\
\hline $\mathbf{1 8}$ & Netherlands & 12 & Ireland & 25 \\
\hline $\mathbf{1 9}$ & Sweden & 19 & United Kingdom & 12 \\
\hline $\mathbf{2 0}$ & Costa Rica & 18 & Colombia & 14 \\
\hline $\mathbf{2 1}$ & Cyprus & 11 & Switzerland & 19 \\
\hline $\mathbf{2 2}$ & Chile & 5 & Belgium & 22 \\
\hline $\mathbf{2 3}$ & United Kingdom & 13 & Cyprus & 9 \\
\hline $\mathbf{2 4}$ & Iceland & 36 & Sweden & 5 \\
\hline $\mathbf{2 5}$ & Switzerland & 16 & Saudi Arabia & 79 \\
\hline
\end{tabular}

Table 11. WHO and Stochastic Frontier Estimated Technical Efficiency

\begin{tabular}{|l|l|c|c|c|c|c|c|}
\hline & & \multicolumn{3}{|c|}{ DALE } & \multicolumn{3}{c|}{ COMP } \\
\hline & & OECD & Non & All & OECD & Non & All \\
\hline Evans & Mean & 0.851 & 0.643 & 0.676 & 0.883 & 0.597 & 0.637 \\
\hline & S.D. & 0.079 & 0.199 & 0.200 & 0.078 & 0.200 & 0.214 \\
\hline & Min & 0.694 & 0.080 & 0.800 & 0.734 & 0.000 & 0.000 \\
\hline & Max & 0.976 & 0.992 & 0.992 & 0.994 & 0.998 & 0.998 \\
\hline & Mean & 0.973 & 0.823 & 0.847 & 0.987 & 0.859 & 0.879 \\
\hline & S.D. & 0.018 & 0.148 & 0.146 & 0.022 & 0.117 & 0.118 \\
\hline & Min & 0.923 & 0.422 & 0.422 & 0.879 & 0.080 & 0.080 \\
\hline & Max & 0.990 & 0.990 & 0.990 & 0.996 & 0.995 & 0.996 \\
\hline Sample Size & 30 & 161 & 191 & 30 & 161 & 191 \\
\hline Correlation & 0.757 & 0.906 & 0.912 & 0.566 & 0.799 & 0.829 \\
\hline
\end{tabular}


The individual results for DALE are shown in Figure 9. The layer of points at the upper right is the OECD observations. The figure bears out the impression in the descriptive statistics, that the variation in technical efficiency is associated with the non-OECD countries. Appendices B and C give the full listing of our results in opposition to those of Evans et al. As is evident from the various descriptors, the change in the results it is fairly substantial.

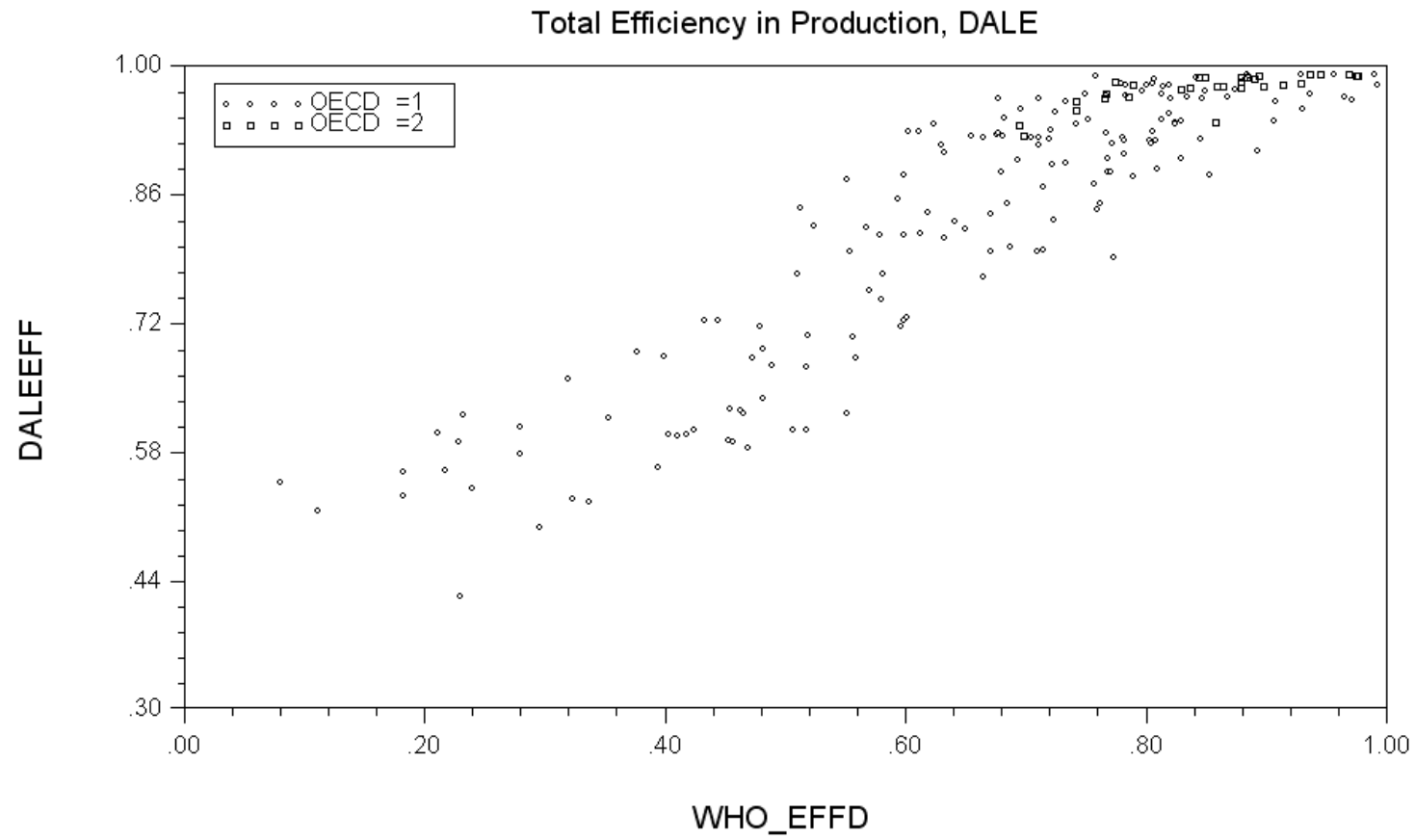

Figure 9: Total Efficiency, DALE 


\subsection{Models with Unmeasured Heterogeneity and Time Varying Inefficiency}

We now examine some formulations that move all time invariant effects out of the distribution of $u_{i t}$. These could be viewed as the most general specifications to be considered. However, in this data set, with almost no within group variation, it seems likely that, in fact, this approach will overspecify the country specific heterogeneity. We present these results to illustrate what should be useful extensions of the stochastic frontier model in data sets with greater within group variation. Results are presented for DALE only. Some of the models are inestimable with COMP (the latent class model, for example). Where both can be fit, the results are similar. In the interest of brevity, only one outcome variable is analyzed.)

A 'true' fixed effects model would appear as

$$
\begin{array}{ll}
y_{i t} & =\alpha_{i}+\mathbf{x}_{i t}{ }^{\prime} \beta+v_{i t}-u_{i t} \\
u_{i t} & =\left|U_{i t}\right| \\
U_{i t} & \sim \mathrm{N}\left[0, \sigma_{u}{ }^{2}\right] .
\end{array}
$$

This differs from the model initially specified in that the inefficiency term $u_{i t}$ is unique in every period for every country. In principle, this is more general than the Schmidt and Sickles formulation - individual heterogeneity and time variation in $u$ are both accommodated. Accommodating measured indicators of heterogeneity, such as per capita income, remains a problem. As we have seen, the random effects formulation can be made general enough that its narrow distributional assumption is probably not restrictive. A 'true ' random effects model at this level of generality would be

$$
y_{i t}=\left(\alpha+w_{i}\right)+\mathbf{z}_{i}^{\prime} \gamma+\mathbf{x}_{i t}^{\prime} \beta+v_{i t}-u_{i t}
$$

This model is fit by maximum simulated likelihood. [See Greene (2001, 2002a).] Figure 10 compares the inefficiency estimates obtained with the two fixed effects models. They are nearly uncorrelated. The random effects estimates bear even less resemblance. Based on all the preceding evidence, it appears that further development of these models is called for. As noted, it seems that these model forms are not suited for this data set. Note the difference in the range of variation in the two sets of values. An appropriate decomposition between heterogeneity and inefficiency likely falls between the two. 
True Fixed Effects vs. Fixed Effects, DALE

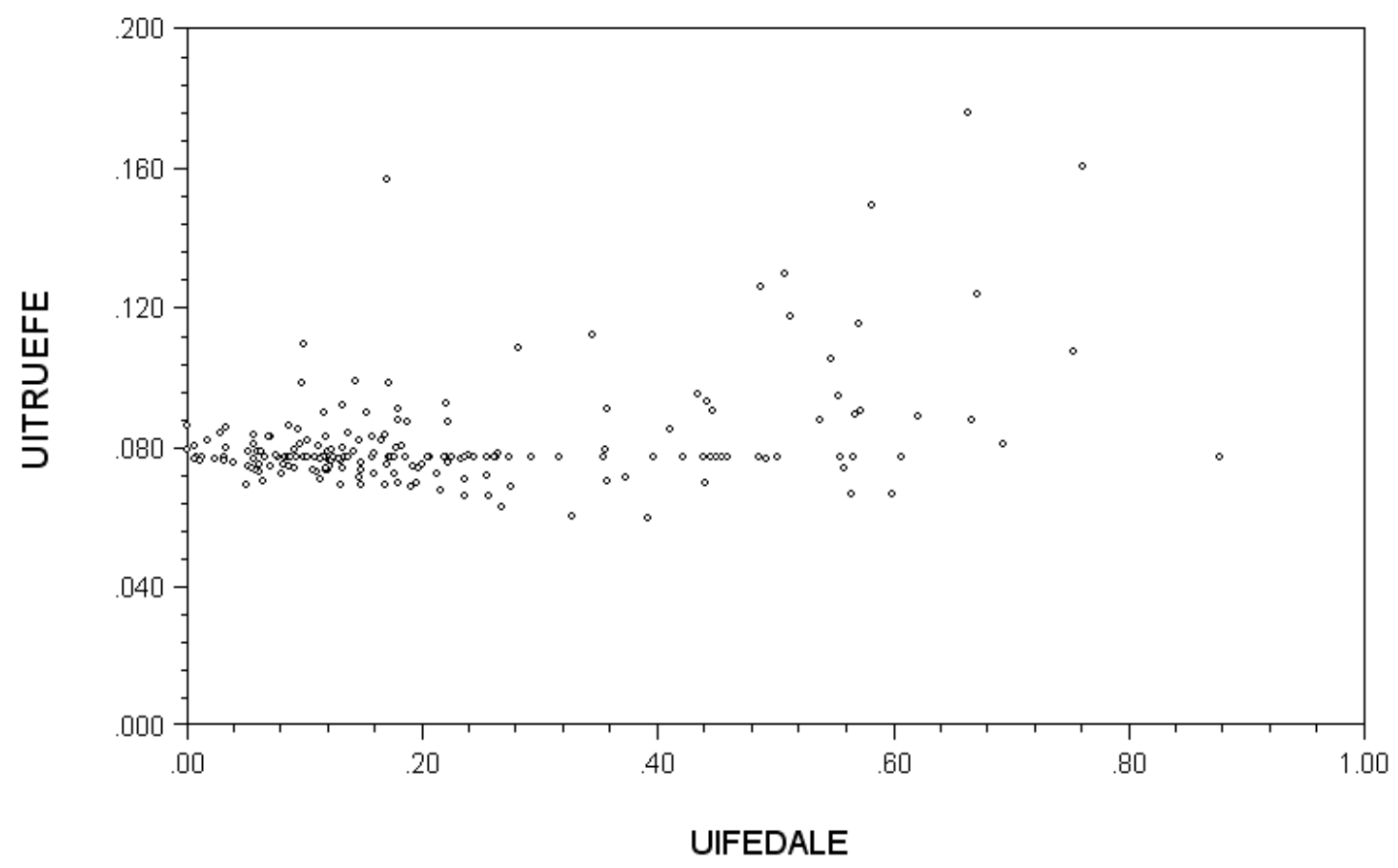

Figure 10: Fixed Effects Estimates

A full random parameters specification of the frontier model would, in principle, capture yet more country specific variation, and isolate the inefficiency in the time varying $u_{i t}$. The estimated structure of a random parameters model for DALE is shown in Table 12. (Annotations are included to clarify the underlying structure.) 
Table 12. Estimated Coefficients of a Random Parameters Model for DALE

\begin{tabular}{|c|c|c|c|c|}
\hline & \multicolumn{4}{|c|}{ Random Coefficient Multiplies Variable } \\
\hline & Constant & Expenditure & Education & Education $^{2}$ \\
\hline \multicolumn{5}{|c|}{ Constant term in the mean of the parameter distribution } \\
\hline Constant & 1.084 & 0.181 & 0.164 & 0.059 \\
\hline \multicolumn{5}{|c|}{ Coefficients on variables that enter the mean of the parameter distribution } \\
\hline Gini & -0.083 & -0.141 & -0.880 & 0.529 \\
\hline GEFF & -0.0617 & 0.00690 & 0.162 & -0.206 \\
\hline Voice & 0.127 & -0.00719 & -0.123 & 0.0849 \\
\hline Pop. Density & 0.0112 & 0.00586 & 0.121 & -0.131 \\
\hline Per Capita GDP & 0.345 & -0.0291 & -0.0686 & 0.104 \\
\hline Tropics & -0.000036 & 0.0236 & -0.566 & 0.0454 \\
\hline Public Finance & 0.00603 & 0.00118 & -0.00172 & -0.00301 \\
\hline OECD & -0.509 & 0.00666 & 0.528 & -0.390 \\
\hline \multicolumn{5}{|c|}{ Standard deviation of the random distribution of the parameter } \\
\hline Std. Deviation & 0.01362 & 0.05605 & 0.09876 & 0.14298 \\
\hline \multicolumn{5}{|c|}{ Parameters of underlying random components } \\
\hline$\sigma_{\mathrm{u}}$ & \multicolumn{4}{|c|}{0.01892} \\
\hline$\sigma_{\mathrm{V}}$ & \multicolumn{4}{|c|}{0.00910} \\
\hline$\lambda$ & \multicolumn{4}{|c|}{2.0776} \\
\hline
\end{tabular}

The estimated correlation matrix of the random parameters is

$$
\mathbf{R}=\left[\begin{array}{cccc}
1 & 0.987 & 0.417 & -0.715 \\
0.987 & 1 & 0.504 & -0.691 \\
0.417 & 0.504 & 1 & -0.500 \\
-0.715 & -0.691 & -0.500 & 1
\end{array}\right]
$$

A major element of the development in this paper is the accommodation of heterogeneity, both measured and unmeasured, in the production parameters and in the inefficiency distribution. Williams (2001) and others have argued that this a particularly important consideration in cross country comparisons of the production of health outcomes. The random parameters model provides an individual specific, posterior estimate of the parameter vector. [See Train (2002) and Greene (2002a) for discussion of the computations. Figure 11 presents kernel density estimators of the posterior distributions of the parameters of the production function across countries. These estimates embody all the sample information on the measured and unmeasured effects in the data. The figures suggest, as have other sources, that there is quite a large range of variation across countries in the parameters of the production function. 


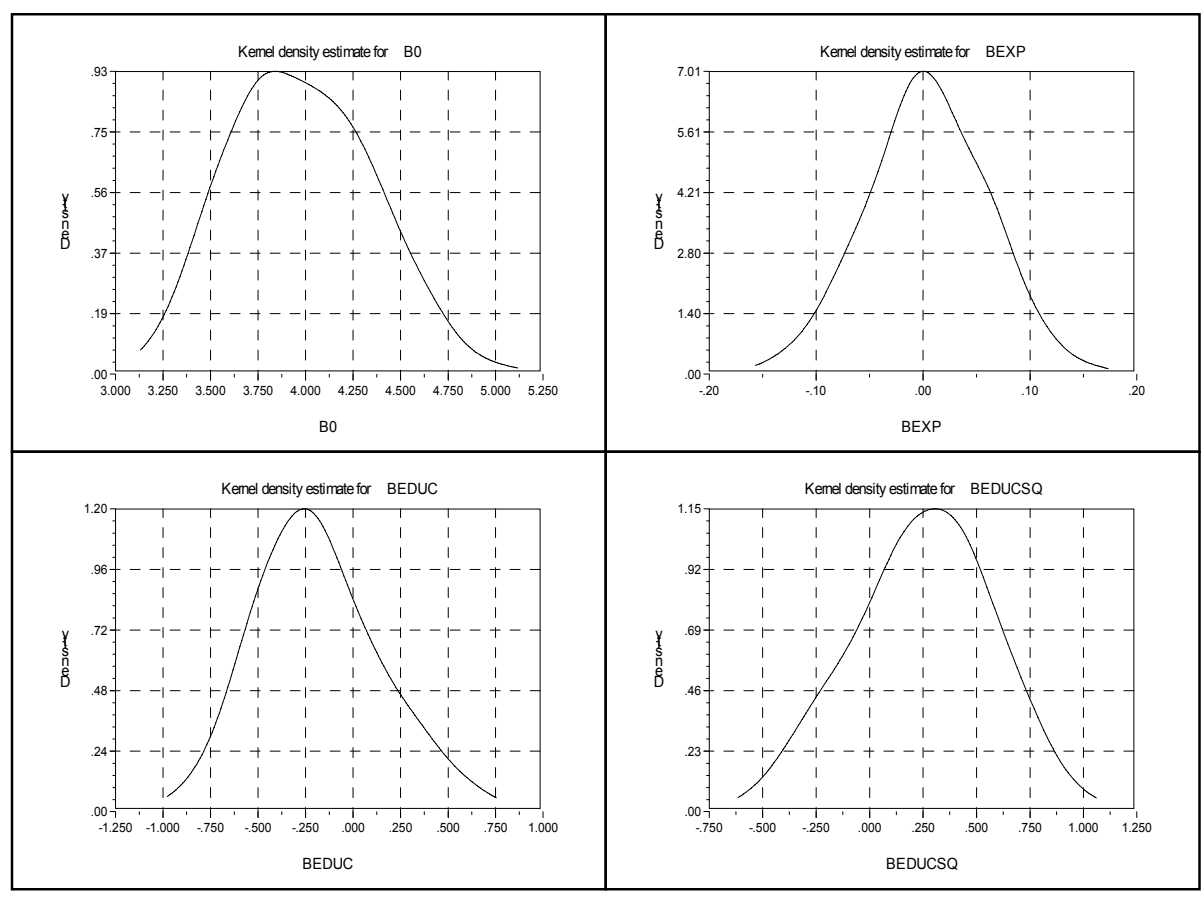

\section{Figure 11: Kernel Density Estimates for Random Parameter Distributions}

Estimates of $u_{i}$ from the random parameters model are computed using the posterior, country specific parameter estimates. The differences between the fixed effects estimates and these in the descriptive statistics in Table 13 suggests the degree to which the random parameters model has absorbed the cross country variation. The correlation between these two sets of estimates is -0.1 ; they are essentially unrelated.

Table 13: Inefficiency Estimates

\begin{tabular}{|l|l|l|l|l|}
\hline & Mean & Std. Deviation & Minimum & Maximum \\
\hline Fixed Effects & 0.222 & 0.186 & 0.000 & 0.876 \\
\hline Random Parameters & 0.0246 & 0.0226 & 0.00130 & 0.0492 \\
\hline
\end{tabular}

The finite mixture (latent class) model is yet another approach to modeling heterogeneity. In this case, the latent heterogeneity is modeled with discrete support, rather than continuous as above. It was not possible to fit any form of finite mixture model with the WHO data; evidently, this model is inconsistent with the data. 


\section{Conclusions}

The WHO data analyzed here include most of the world's countries and embody nearly its entire population. The original studies by Evans et al. were an innovative, large scale effort to compare these countries on the effectiveness of delivery of health care using two measures, disability adjusted life expectancy (DALE) and a recently developed composite measure of health care delivery (COMP). The authors used a panel data technique based on the fixed effects regression model to obtain both quantitative measures of effectiveness and simple rankings for each country. Subsequent researchers have analyzed these same data, but generally provided descriptive statistics for the same measures that more or less agreed with the original results. This study has continued that analysis, with several extensions. First, the model used is considerably more general than those used previously. Second, we have incorporated measured indicators of cross country heterogeneity in the estimates. Third, we have produced an alternative set of individual country specific efficiency measures and country ranks. Our results differ substantially from those obtained by the authors of the original studies.

This reanalysis of the WHO data was motivated by several considerations.

- Both the fixed effects approach used earlier, and several others that have appeared in received studies make no distinction between technical inefficiency and cross country heterogeneity. Thus, some of what was reported as measured inefficiency should instead be treated as heterogeneity. Decomposing a two part unmeasured effect is a difficult exercise. The several models proposed here do so to varying degrees, ranging from none in the received models to, probably, excessively in the new techniques presented in the final section of this paper. We find, in our preferred specification, that making this distinction brings a substantial change in the estimated results.

- The fixed effects model used in Evans et. al. (2000a,b) does not allow the analyst to make use of measured effects that capture some of the cross country heterogeneity in the data. The models proposed here can accommodate these variables. We find including these measured indicators, such as per capita income and a measure of income distribution, noticeable changes in the estimated results.

- Being a rich panel data set, the WHO data present an opportunity to examine the behavior of new techniques which are better suited to studying heterogeneous data than were used earlier. The methodological sections of this paper have described a wide variety of panel data estimators for the stochastic frontier model.

We have obtained a number of empirical results. In formulating the production function, we confirm what earlier researchers have found with respect to the income elasticity of health expenditure. Our estimates range from 1.08 to 1.23 , with much larger values for the wealthier OECD countries than for the remaining countries in the sample. A number of earlier studies have examined the relationship between income (measured 
by per capita GDP) and health outcomes, and found a weak to nonexistent support. We find a persistent, significant impact of income, both on outcomes as well as the efficiency of distribution. Likewise, the distribution of income has been suggested as an important influence, but prior results were somewhat inconclusive. As in the case of income, itself, we find significant explanatory power in the distribution of income. It should be noted that in both these cases, and throughout this study, the distinction between OECD and non-OECD countries, which explains much of the variation in these measures, also explains much of the variation in health outcomes and in the efficiency of delivery of them.

Our final results are presented in Section 5.5 and in Appendices B and C. These are our alternatives to the those in the original studies. It should be emphasized, the measures and rankings in the tables pertain to the efficiency of delivery of health outcomes, not to absolute levels of those outcomes. Our results do not comment on the levels of health attainment in the countries contained in this data set. 


\section{Appendix A. Missing and Imputed Data in The World Health Organization WHR Data Set}

The country level sample contained missing values for three variables, population density (PopDen), government effectiveness (GEFF) and democratization (Voice).

Data on population density were missing for the 18 countries listed in Table A.1 below. The website http://www.geography.about.com/library/cia/blcindex.htm contains year 2000 data on land area and population for the countries for which our data were missing. The table lists the country names and extracted data. The population density was calculated by drawing the year 2000 estimated population back to 1997 using the estimated population growth rate for three years, then computing the density in persons per square kilometer.

\begin{tabular}{|l|r|r|c|}
\hline \multicolumn{4}{|c|}{ Table A.1. Extracted Data for Constructing Missing Population Density } \\
\hline Country & Land Area & Population (2000) & Pop. Growth Rate \\
\hline Bosnia & 51,129 & $3,835,777$ & $+3.1 \%$ \\
\hline Belarus & 207,600 & $10,366,719$ & $-0.2 \%$ \\
\hline Cook Islands & 240 & 20,407 & $+1.6 \%$ \\
\hline Czechoslovakia & 72,276 & $10,272,179$ & $-0.8 \%$ \\
\hline Croatia & 56,410 & $4,282.216$ & $+0.9 \%$ \\
\hline Kyrgisztan & 191,300 & $4,685,230$ & $+1.4 \%$ \\
\hline Macedonia & 24,586 & $2,041,467$ & $+0.1 \%$ \\
\hline Marshall Islands & 181.3 & 18,126 & $+3.9 \%$ \\
\hline Nauru & 21 & 11,845 & $+0.2 \%$ \\
\hline Niue & 260 & 26,937 & $+1.5 \%$ \\
\hline Palau & 458 & 18,766 & $+1.8 \%$ \\
\hline Slovakia & 48,800 & $5,407,956$ & $+0.1 \%$ \\
\hline Slovenia & 20253 & $1,927,593$ & $+0.1 \%$ \\
\hline Tuvalu & 26 & 10,838 & $+1.4 \%$ \\
\hline Turkmenistan & 488,100 & $4,518,268$ & $+1.9 \%$ \\
\hline Yugoslavia & 102,136 & $10,662,087$ & $+0 / 8 \%$ \\
\hline San Marino & 60.5 & 2,113 & $+0.5 \%$ \\
\hline Dem. Rep. Congo & $2,267,600$ & $51,964,999$ & $+3.2 \%$ \\
\hline
\end{tabular}

The government effectiveness and popular voice variables are measures of the responsiveness of the government to the underlying populace. They are discussed, for example, at www.worldbank.org/wbi/governance. The government effectiveness variable (GEFF) is missing from the WHO data set for the 39 countries listed in Table A.2 below. Of these 39, 21 are also missing the VOICE variable. No countries are missing VOICE but not GEFF. A total of 83 observations are missing GEFF and 29 are missing VOICE. The website www.worldbank.org/wbi/governance/zips/aggind-data.xls provides data from several extensive studies of governance of 174 countries. Some of these were useable for filling in the gaps in the preceding data. Data for GEFF for the following countries were obtained from this source: Afghanistan (a), Barbados (b), Belize (a), Djibouti (b), Dominica, Eritrea (a,b), Equatorial Guinea (b), Cambodia (a), Laos (a), 
Mauritania, Nepal, Rwanda, Burundi, Cape Verde, where (a) indicates that the value was from a year 2000 study and (b) indicates that a proxy, 'Rule of Law' was used.

\begin{tabular}{|l|l|l|}
\hline Table A.2. Missing Data on Government Effectiveness & GEFF) \\
\hline Cook Islands (2) & Dominica (2), (3) & Mauritania (1), (3) \\
\hline Andorra (2) & Eritrea (3) & Nepal (1), (3) \\
\hline Afghanistan (3) & Micronesia (2) & Nauru (2) \\
\hline Antigua (2) & Equatorial Guinea (1), (3) & Palau (2) \\
\hline San Marino (2) & Grenada (2) & Rwanda (1), (3) \\
\hline Burundi (1), (3) & Cambodia (3) & Solomon Islands \\
\hline Belize (3) & Kiribati (2) & Sao Tome \\
\hline Barbados (1), (3) & St. Kitts (2) & Seychelles (2) \\
\hline Bhutan & Laotian PDR (3) & Tuvalu (2) \\
\hline Niue (2) & St. Lucia (2) & Tonga (1), (2) \\
\hline Comorros (1) & Monaco (2) & St. Vincent (2) \\
\hline Cape Verde (1), (3) & Maldives (1) & Vanuatu (2) \\
\hline Djibouti (3) & Marshall Islands (2) & Samoa (1), (2) \\
\hline (1) Country observed for 5 years 1993-1997. (Others only observed for one year) \\
\hline (2) Also missing VOICE \\
\hline (3) Data for this country completed from additional sources noted in the text. \\
\hline
\end{tabular}

No source for filling in the remaining observations for these variables could be located. The remaining 41 observations on GEFF and 28 on Voice were filled in by using the predictions produced by a linear regression of these variables on the 1997 values all of the other exogenous variables in the data set, including the inputs in the production function. (The $R^{2} \mathrm{~s}$ in these regressions were 0.61 for Voice and 0.61 for GEFF.) This will produce a small amount of measurement error in two of the eight covariates. Since these observations constitute only about $5.4 \%$ of the sample of 754 observations and represent the very smallest countries in the data set, this should not materially affect the empirical results.

The sample contains data on 191 countries. Of these 191 countries, 140 were observed in all 5 years (11 of them incompletely as shown in Table A.2), one (Algeria) was observed in 4 years (1996 is missing) and 50 were observed only in 1997 . We elected not to fill in the 1996 data for Algeria, primarily because none of the estimators discussed in the text or estimated in the empirical results actually requires a balanced panel and, secondarily, because the crucial health expenditure variable does not vary smoothly over the sample period for this country. Interpolation methods based on constant growth rates for this small number of years seemed likely to be quite inaccurate. The final sample contains a total of 754 observations. 


\begin{tabular}{|c|c|c|c|c|}
\hline Country & RANK & Efficiency & WHO Rank & WHO Efficiency \\
\hline Japan & 1 & .98995 & 9 & .94500 \\
\hline Greece & 2 & .98986 & 11 & .93600 \\
\hline Jamaica & 3 & .98972 & 8 & .95600 \\
\hline Spain & 4 & .98954 & 6 & .96800 \\
\hline Chile & 5 & .98944 & 23 & .88400 \\
\hline Singapore & 6 & .98896 & 14 & .92900 \\
\hline Malta & 7 & .98868 & 2 & .98900 \\
\hline France & 8 & .98857 & 4 & .97400 \\
\hline Georgia & 9 & .98816 & 84 & .75800 \\
\hline Italy & 10 & .98814 & 3 & .97600 \\
\hline Cyprus & 11 & .98777 & 22 & .88500 \\
\hline Netherlands & 12 & .98754 & 19 & .89300 \\
\hline United Kingdom & 13 & .98657 & 24 & .88300 \\
\hline Canada & 14 & .98647 & 35 & .84900 \\
\hline Australia & 15 & .98605 & 39 & .84400 \\
\hline Switzerland & 16 & .98572 & 26 & .87900 \\
\hline Israel & 17 & .98568 & 40 & .84100 \\
\hline Costa Rica & 18 & .98529 & 25 & .88200 \\
\hline Sweden & 19 & .98510 & 21 & .89000 \\
\hline Armenia & 20 & .98492 & 56 & .80600 \\
\hline Belgium & 21 & .98117 & 28 & .87800 \\
\hline United States of America & 22 & .98083 & 72 & .77400 \\
\hline Portugal & 23 & .98033 & 13 & .92900 \\
\hline Argentina & 24 & .97996 & 71 & .77900 \\
\hline Croatia & 25 & .97963 & 57 & .80500 \\
\hline Austria & 26 & .97871 & 15 & .91400 \\
\hline Oman & 27 & .97865 & 1 & .99200 \\
\hline China & 28 & .97863 & 61 & .80000 \\
\hline Panama & 29 & .97827 & 67 & .78300 \\
\hline Mexico & 30 & .97822 & 63 & .78900 \\
\hline Uruguay & 31 & .97777 & 50 & .81900 \\
\hline Norway & 32 & .97714 & 18 & .89700 \\
\hline Luxembourg & 33 & .97662 & 31 & .86400 \\
\hline Ireland & 34 & .97632 & 32 & .85900 \\
\hline Colombia & 35 & .97560 & 51 & .81400 \\
\hline Iceland & 36 & .97490 & 27 & .87900 \\
\hline Germany & 37 & .97479 & 41 & .83600 \\
\hline Venezuela & 38 & .97387 & 29 & .87300 \\
\hline Finland & 39 & .97253 & 44 & .82900 \\
\hline Slovenia & 40 & .97156 & 62 & .79700 \\
\hline Cuba & 41 & .97127 & 36 & .84900 \\
\hline Saudi Arabia & 42 & .96880 & 10 & .93600 \\
\hline Barbados & 43 & .96857 & 87 & .74900 \\
\hline Paraguay & 44 & .96791 & 52 & .81300 \\
\hline New Zealand & 45 & .96754 & 80 & .76600 \\
\hline Sri Lanka & 46 & .96678 & 66 & .78300 \\
\hline Trinidad and Tobago & 47 & .96651 & 79 & .76700 \\
\hline Bahrain & 48 & .96572 & 30 & .86700 \\
\hline Andorra & 49 & .96565 & 7 & .96400 \\
\hline Dominican Republic & 50 & .96547 & 42 & .83400 \\
\hline Denmark & 51 & .96498 & 65 & .78500 \\
\hline Ukraine & 52 & .96364 & 101 & .71100 \\
\hline Tonga & 53 & .96346 & 114 & .67700 \\
\hline Czech Republic & 54 & .96326 & 81 & .76500 \\
\hline Honduras & 55 & .96319 & 48 & .82000 \\
\hline El Salvador & 56 & .96248 & 37 & .84600 \\
\hline San Marino & 57 & .96180 & 5 & .97100 \\
\hline Poland & 58 & .96066 & 89 & .74200 \\
\hline United Arab Emirates & 59 & .96066 & 16 & .90700 \\
\hline Bulgaria & 60 & .95935 & 92 & .73300 \\
\hline Monaco & 61 & .95229 & 12 & .93000 \\
\hline Republic of Moldavia & 62 & .95160 & 106 & .69600 \\
\hline Slovakia & 63 & .94969 & 88 & .74200 \\
\hline Lithuania & 64 & .94784 & 93 & .72400 \\
\hline Grenada & 65 & .94761 & 49 & .81900 \\
\hline Romania & 66 & .94188 & 111 & .68200 \\
\hline Qatar & 67 & .94110 & 53 & .81300 \\
\hline Malaysia & 68 & .94037 & 86 & .75100 \\
\hline
\end{tabular}




\begin{tabular}{|c|c|c|c|c|}
\hline Morocco & 69 & .93864 & 17 & .90600 \\
\hline Algeria & 70 & .93821 & 45 & .82900 \\
\hline Turkey & 71 & .93697 & 33 & .85800 \\
\hline Tunisia & 72 & .93644 & 46 & .82400 \\
\hline Yugoslavia & 73 & .93556 & 47 & .82400 \\
\hline Russian Federation & 74 & .93531 & 127 & .62300 \\
\hline Indonesia & 75 & .93527 & 90 & .74100 \\
\hline Republic of Korea & 76 & .93361 & 107 & .69400 \\
\hline Ecuador & 77 & .92845 & 96 & .72100 \\
\hline Iran (Islamic Republic) & 78 & .92804 & 58 & .80500 \\
\hline Viet Nam & 79 & .92799 & 130 & .61100 \\
\hline Samoa & 80 & .92768 & 131 & .60200 \\
\hline Estonia & 81 & .92615 & 115 & .67700 \\
\hline Brazil & 82 & .92591 & 78 & .76700 \\
\hline Belarus & 83 & .92337 & 116 & .67600 \\
\hline Uzbekistan & 84 & .92269 & 112 & .68100 \\
\hline Hungary & 85 & .92256 & 105 & .69800 \\
\hline Latvia & 86 & .92241 & 121 & .65500 \\
\hline Bosnia and Herzegovina & 87 & .92102 & 70 & .78000 \\
\hline Thailand & 88 & .92081 & 102 & .71000 \\
\hline Guyana & 89 & .92081 & 104 & .70400 \\
\hline Peru & 90 & .92009 & 119 & .66500 \\
\hline Saint Vincent & 91 & .91975 & 38 & .84500 \\
\hline Lebanon & 92 & .91875 & 97 & .71900 \\
\hline Cape Verde & 93 & .91813 & 55 & .80800 \\
\hline Azerbaijan & 94 & .91794 & 60 & .80300 \\
\hline Kuwait & 95 & .91773 & 68 & .78200 \\
\hline Dominica & 96 & .91470 & 59 & .80400 \\
\hline Nicaragua & 97 & .91410 & 74 & .77200 \\
\hline Jordan & 98 & .91287 & 100 & .71100 \\
\hline Philippines & 99 & .91221 & 126 & .63000 \\
\hline Solomon Islands & 100 & .90578 & 20 & .89200 \\
\hline Fiji & 101 & .90471 & 124 & .63200 \\
\hline The Former Yugoslavian Rep & 102 & .90286 & 69 & .78100 \\
\hline Egypt & 103 & .89824 & 43 & .82900 \\
\hline Suriname & 104 & .89732 & 77 & .76800 \\
\hline Niue & 105 & .89580 & 108 & .69300 \\
\hline Syrian Arab Republic & 106 & .89256 & 91 & .73300 \\
\hline Cook Islands & 107 & .89213 & 95 & .72200 \\
\hline Saint Lucia & 108 & .88615 & 54 & .80900 \\
\hline Brunei Darussalam & 109 & .88375 & 76 & .76800 \\
\hline Iraq & 110 & .88364 & 75 & .77000 \\
\hline Mauritius & 111 & .88315 & 113 & .67900 \\
\hline Belize & 112 & .88015 & 34 & .85300 \\
\hline Kazakhstan & 113 & .88006 & 135 & .59800 \\
\hline Albania & 114 & .87901 & 64 & .78900 \\
\hline Tajikistan & 115 & .87539 & 145 & .55100 \\
\hline Pakistan & 116 & .86955 & 85 & .75700 \\
\hline Guatemala & 117 & .86736 & 99 & .71400 \\
\hline Bahamas & 118 & .85409 & 137 & .59300 \\
\hline Micronesia & 119 & .84947 & 110 & .68400 \\
\hline Yemen & 120 & .84835 & 82 & .76100 \\
\hline Turkmenistan & 121 & .84404 & 152 & .51300 \\
\hline Seychelles & 122 & .84309 & 83 & .75900 \\
\hline Tuvalu & 123 & .83999 & 128 & .61800 \\
\hline India & 124 & .83700 & 118 & .67000 \\
\hline Libya & 125 & .83116 & 94 & .72300 \\
\hline Antigua and Barbuda & 126 & .83023 & 123 & .64100 \\
\hline Maldives & 127 & .82478 & 147 & .52400 \\
\hline Bolivia & 128 & .82294 & 142 & .56700 \\
\hline Saint Kitts and Nevis & 129 & .82132 & 122 & .65000 \\
\hline Myanmar & 130 & .81612 & 129 & .61200 \\
\hline Kyrgyzstan & 131 & .81475 & 134 & .59800 \\
\hline Marshall Islands & 132 & .81450 & 140 & .57900 \\
\hline Palau & 133 & .81203 & 125 & .63200 \\
\hline Gambia & 134 & .80110 & 109 & .68700 \\
\hline Nepal & 135 & .79902 & 98 & .71400 \\
\hline Bangladesh & 136 & .79749 & 103 & .70900 \\
\hline Kiribati & 137 & .79723 & 144 & .55400 \\
\hline Sao Tome & 138 & .79710 & 117 & .67100 \\
\hline Bhutan & 139 & .79090 & 73 & .77300 \\
\hline Democratic P.R. Korea & 140 & .77266 & 153 & .51000 \\
\hline
\end{tabular}




\begin{tabular}{|c|c|c|c|c|}
\hline Mongolia & 141 & .77230 & 138 & .58100 \\
\hline Vanuatu & 142 & .76857 & 120 & .66500 \\
\hline Comoros & 143 & .75474 & 141 & .57000 \\
\hline Haiti & 144 & .74412 & 139 & .58000 \\
\hline Senegal & 145 & .72461 & 132 & .60100 \\
\hline Cote d'Ivoire & 146 & .72247 & 133 & .59800 \\
\hline Nauru & 147 & .72161 & 166 & .44400 \\
\hline Congo & 148 & .72142 & 167 & .43300 \\
\hline Benin & 149 & .71497 & 136 & .59600 \\
\hline Ghana & 150 & .71478 & 158 & .47900 \\
\hline Sudan & 151 & .70629 & 149 & .51900 \\
\hline Papua New Guinea & 152 & .70407 & 146 & .55600 \\
\hline Cambodia & 153 & .69115 & 157 & .48100 \\
\hline Equatorial Guinea & 154 & .68726 & 174 & .37700 \\
\hline Cameroon & 155 & .68217 & 172 & .39900 \\
\hline Gabon & 156 & .68150 & 143 & .55900 \\
\hline Togo & 157 & .68140 & 159 & .47200 \\
\hline Lao People's Dem. Rep. & 158 & .67291 & 155 & .48900 \\
\hline Mauritania & 159 & .67145 & 151 & .51700 \\
\hline Kenya & 160 & .65768 & 178 & .32000 \\
\hline Guinea-Bissau & 161 & .63717 & 156 & .48100 \\
\hline Central African & 162 & .62496 & 164 & .45400 \\
\hline Burkina Faso & 163 & .62334 & 162 & .46300 \\
\hline Eritrea & 164 & .62065 & 148 & .55100 \\
\hline Chad & 165 & .62047 & 161 & .46500 \\
\hline South Africa & 166 & .61981 & 182 & .23200 \\
\hline Nigeria & 167 & .61557 & 175 & .35300 \\
\hline United Rep. of Tanzania & 168 & .60578 & 180 & .27900 \\
\hline Afghanistan & 169 & .60279 & 150 & .51700 \\
\hline Somalia & 170 & .60202 & 154 & .50600 \\
\hline Mozambique & 171 & .60188 & 168 & .42400 \\
\hline Lesotho & 172 & .59987 & 186 & .21100 \\
\hline Ethiopia & 173 & .59846 & 169 & .41800 \\
\hline Burundi & 174 & .59793 & 171 & .40300 \\
\hline Mali & 175 & .59596 & 170 & .41000 \\
\hline Angola & 176 & .59144 & 165 & .45300 \\
\hline Swaziland & 177 & .59040 & 184 & .22900 \\
\hline Djibouti & 178 & .58910 & 163 & .45700 \\
\hline Guinea & 179 & .58299 & 160 & .46900 \\
\hline Uganda & 180 & .57682 & 179 & .28000 \\
\hline Madagascar & 181 & .56203 & 173 & .39400 \\
\hline Democratic Rep. of Congo & 182 & .55903 & 185 & .21700 \\
\hline Namibia & 183 & .55690 & 189 & .18300 \\
\hline Zimbabwe & 184 & .54566 & 191 & .08000 \\
\hline Rwanda & 185 & .53973 & 181 & .24000 \\
\hline Botswana & 186 & .53128 & 188 & .18300 \\
\hline Niger & 187 & .52835 & 177 & .32300 \\
\hline Liberia & 188 & .52480 & 176 & .33700 \\
\hline Zambia & 189 & .51470 & 190 & .11200 \\
\hline Malawi & 190 & .49676 & 187 & .29600 \\
\hline Sierra Leone & 191 & .42205 & 183 & .23000 \\
\hline
\end{tabular}




\begin{tabular}{|c|c|c|c|c|}
\hline Country & RANK & Efficiency & WHO Rank & WHO Efficiency \\
\hline Greece & 1 & .99563 & 14 & .93300 \\
\hline Spain & 2 & .99558 & 7 & .97200 \\
\hline Japan & 3 & .99547 & 10 & .95700 \\
\hline Costa Rica & 4 & .99539 & 36 & .84900 \\
\hline Sweden & 5 & .99528 & 23 & .90800 \\
\hline Malta & 6 & .99524 & 5 & .97800 \\
\hline Netherlands & 7 & .99515 & 17 & .92800 \\
\hline Singapore & 8 & .99514 & 6 & .97300 \\
\hline Cyprus & 9 & .99495 & 24 & .90600 \\
\hline Norway & 10 & .99486 & 11 & .95500 \\
\hline Italy & 11 & .99474 & 2 & .99100 \\
\hline United Kingdom & 12 & .99471 & 18 & .92500 \\
\hline Philippines & 13 & .99467 & 60 & .75500 \\
\hline Colombia & 14 & .99463 & 22 & .91000 \\
\hline France & 15 & .99460 & 1 & .99400 \\
\hline Israel & 16 & .99460 & 28 & .88400 \\
\hline Austria & 17 & .99449 & 9 & .95900 \\
\hline Australia & 18 & .99438 & 32 & .87600 \\
\hline Switzerland & 19 & .99430 & 20 & .91600 \\
\hline Canada & 20 & .99418 & 30 & .88100 \\
\hline Iceland & 21 & .99407 & 15 & .93200 \\
\hline Belgium & 22 & .99407 & 21 & .91500 \\
\hline Finland & 23 & .99403 & 31 & .88100 \\
\hline Barbados & 24 & .99399 & 46 & .80800 \\
\hline Ireland & 25 & .99376 & 19 & .92400 \\
\hline Denmark & 26 & .99331 & 34 & .86200 \\
\hline Germany & 27 & .99325 & 25 & .90200 \\
\hline New Zealand & 28 & .99323 & 41 & .82700 \\
\hline Slovenia & 29 & .99318 & 38 & .83800 \\
\hline Luxembourg & 30 & .99310 & 16 & .92800 \\
\hline Czech Republic & 31 & .99295 & 48 & .80500 \\
\hline Portugal & 32 & .99268 & 12 & .94500 \\
\hline Poland & 33 & .99228 & 50 & .79300 \\
\hline Croatia & 34 & .99145 & 43 & .81200 \\
\hline United States of America & 35 & .99018 & 37 & .83800 \\
\hline Chile & 36 & .98872 & 33 & .87000 \\
\hline Thailand & 37 & .98871 & 47 & .80700 \\
\hline Jamaica & 38 & .98762 & 53 & .78200 \\
\hline Ukraine & 39 & .98752 & 79 & .70800 \\
\hline Slovakia & 40 & .98483 & 62 & .75400 \\
\hline Oman & 41 & .98411 & 8 & .96100 \\
\hline Trinidad and Tobago & 42 & .98403 & 67 & .74200 \\
\hline Sri Lanka & 43 & .98361 & 76 & .71600 \\
\hline Malaysia & 44 & .97855 & 49 & .80200 \\
\hline Lithuania & 45 & .97675 & 73 & .72200 \\
\hline Hungary & 46 & .97655 & 66 & .74300 \\
\hline Dominican Republic & 47 & .97643 & 51 & .78900 \\
\hline Republic of Korea & 48 & .97475 & 58 & .75900 \\
\hline Belarus & 49 & .97321 & 72 & .72300 \\
\hline Estonia & 50 & .97189 & 77 & .71400 \\
\hline Tonga & 51 & .96930 & 116 & .60700 \\
\hline Kazakhstan & 52 & .96788 & 64 & .75200 \\
\hline Samoa & 53 & .96550 & 119 & .58900 \\
\hline Nicaragua & 54 & .96534 & 71 & .73300 \\
\hline Mexico & 55 & .96528 & 61 & .75500 \\
\hline Republic of Moldavia & 56 & .96366 & 101 & .63900 \\
\hline Georgia & 57 & .96341 & 114 & .61500 \\
\hline Andorra & 58 & .96270 & 4 & .98200 \\
\hline San Marino & 59 & .96003 & 3 & .99800 \\
\hline Morocco & 60 & .95909 & 29 & .88200 \\
\hline Cuba & 61 & .95889 & 39 & .83400 \\
\hline Romania & 62 & .95757 & 99 & .64500 \\
\hline Uruguay & 63 & .95673 & 65 & .74500 \\
\hline Venezuela & 64 & .95665 & 54 & .77500 \\
\hline Fiji & 65 & .95648 & 96 & .65300 \\
\hline Armenia & 66 & .95552 & 104 & .63000 \\
\hline Panama & 67 & .95319 & 95 & .65600 \\
\hline Dominica & 68 & .95300 & 35 & .85400 \\
\hline
\end{tabular}




\begin{tabular}{|c|c|c|c|c|}
\hline Monaco & 69 & .95125 & 13 & .94300 \\
\hline Senegal & 70 & .95024 & 59 & .75600 \\
\hline Bulgaria & 71 & .94738 & 102 & .63900 \\
\hline Latvia & 72 & .94234 & 105 & .63000 \\
\hline Jordan & 73 & .94147 & 83 & .69800 \\
\hline Argentina & 74 & .94104 & 75 & .72200 \\
\hline Paraguay & 75 & .94030 & 57 & .76100 \\
\hline Mauritius & 76 & .93542 & 84 & .69100 \\
\hline Tunisia & 77 & .93226 & 52 & .78500 \\
\hline United Arab Emirates & 78 & .92971 & 27 & .88600 \\
\hline Saudi Arabia & 79 & .92795 & 26 & .89400 \\
\hline Kuwait & 80 & .92692 & 45 & .81000 \\
\hline Ecuador & 81 & .92499 & 111 & .61900 \\
\hline Guyana & 82 & .92319 & 128 & .55400 \\
\hline Indonesia & 83 & .92173 & 92 & .66000 \\
\hline Qatar & 84 & .91881 & 44 & .81200 \\
\hline Bahrain & 85 & .91658 & 42 & .82400 \\
\hline Brunei Darussalam & 86 & .91510 & 40 & .82900 \\
\hline Egypt & 87 & .91062 & 63 & .75200 \\
\hline Benin & 88 & .91018 & 97 & .64700 \\
\hline Guatemala & 89 & .90991 & 78 & .71300 \\
\hline Cape Verde & 90 & .90790 & 113 & .61700 \\
\hline Bolivia & 91 & .90318 & 126 & .57100 \\
\hline Lebanon & 92 & .90057 & 91 & .66400 \\
\hline Albania & 93 & .89972 & 55 & .77400 \\
\hline Comoros & 94 & .89914 & 118 & .59200 \\
\hline Grenada & 95 & .89711 & 85 & .68900 \\
\hline India & 96 & .89579 & 112 & .61700 \\
\hline Uzbekistan & 97 & .89430 & 117 & .59900 \\
\hline Solomon Islands & 98 & .89329 & 80 & .70500 \\
\hline Niue & 99 & .89247 & 121 & .58400 \\
\hline Bangladesh & 100 & .88931 & 88 & .67500 \\
\hline Saint Vincent & 101 & .88918 & 74 & .74400 \\
\hline Bahamas & 102 & .88712 & 94 & .66700 \\
\hline Algeria & 103 & .88461 & 81 & .70100 \\
\hline Palau & 104 & .88457 & 82 & .70000 \\
\hline El Salvador & 105 & .88376 & 115 & .60800 \\
\hline Cook Islands & 106 & .88292 & 107 & .62800 \\
\hline Saint Lucia & 107 & .88284 & 68 & .74000 \\
\hline Belize & 108 & .88176 & 69 & .73600 \\
\hline Yemen & 109 & .88090 & 120 & .58700 \\
\hline Bosnia and Herzegovina & 110 & .87976 & 90 & .66400 \\
\hline Turkey & 111 & .87929 & 70 & .73400 \\
\hline The former Yugoslav Rep. & 112 & .87888 & 89 & .66400 \\
\hline Peru & 113 & .87702 & 129 & .54700 \\
\hline Seychelles & 114 & .87663 & 56 & .77300 \\
\hline Russian Federation & 115 & .87444 & 130 & .54400 \\
\hline Honduras & 116 & .87434 & 131 & .54400 \\
\hline Antigua and Barbuda & 117 & .87247 & 86 & .68800 \\
\hline Ghana & 118 & .87084 & 135 & .52200 \\
\hline Iran (Islamic Republic) & 119 & .86903 & 93 & .65900 \\
\hline Kenya & 120 & .86894 & 140 & .50500 \\
\hline Suriname & 121 & .86669 & 110 & .62300 \\
\hline Azerbaijan & 122 & .85956 & 109 & .62600 \\
\hline Syrian Arab Republic & 123 & .85939 & 108 & .62800 \\
\hline Nauru & 124 & .85802 & 98 & .64700 \\
\hline Brazil & 125 & .85474 & 125 & .57300 \\
\hline Irag & 126 & .85245 & 103 & .63700 \\
\hline Pakistan & 127 & .85225 & 122 & .58300 \\
\hline Micronesia & 128 & .85142 & 123 & .57900 \\
\hline Burkina Faso & 129 & .85032 & 132 & .54300 \\
\hline Viet Nam & 130 & .84961 & 160 & .39300 \\
\hline Yugoslavia & 131 & .84912 & 106 & .62900 \\
\hline Saint Kitts and Nevis & 132 & .84414 & 100 & .64300 \\
\hline Maldives & 133 & .84381 & 147 & .47700 \\
\hline Sudan & 134 & .84211 & 134 & .52400 \\
\hline Haiti & 135 & .84187 & 138 & .51700 \\
\hline Kiribati & 136 & .84174 & 142 & .50500 \\
\hline Burundi & 137 & .84171 & 143 & .49400 \\
\hline United Republic Tanzania & 138 & .84096 & 156 & .42200 \\
\hline Tajikistan & 139 & .84034 & 154 & .42800 \\
\hline Uganda & 140 & .83767 & 149 & .46400 \\
\hline
\end{tabular}




\begin{tabular}{|c|c|c|c|c|}
\hline Marshall Islands & 141 & .83152 & 141 & .50500 \\
\hline Tuvalu & 142 & .82982 & 136 & .51800 \\
\hline Turkmenistan & 143 & .82702 & 153 & .44300 \\
\hline Cote d'Ivoire & 144 & .82596 & 137 & .51700 \\
\hline China & 145 & .82267 & 144 & .48500 \\
\hline Zimbabwe & 146 & .81330 & 155 & .42700 \\
\hline Libya & 147 & .81291 & 87 & .68300 \\
\hline Togo & 148 & .81132 & 152 & .44900 \\
\hline Gambia & 149 & .80615 & 146 & .48200 \\
\hline Sao Tome & 150 & .80366 & 133 & .53500 \\
\hline Vanuatu & 151 & .80149 & 127 & .55900 \\
\hline Mongolia & 152 & .80027 & 145 & .48300 \\
\hline Malí & 153 & .78950 & 163 & .36100 \\
\hline Nepal & 154 & .78636 & 150 & .45700 \\
\hline Kyrgyzstan & 155 & .78295 & 151 & .45500 \\
\hline Congo & 156 & .77985 & 166 & .35400 \\
\hline Cameroon & 157 & .77430 & 164 & .35700 \\
\hline Bhutan & 158 & .77246 & 124 & .57500 \\
\hline Rwanda & 159 & .77204 & 172 & .32700 \\
\hline Zambia & 160 & .76247 & 182 & .26900 \\
\hline Mauritania & 161 & .76243 & 162 & .38400 \\
\hline Namibia & 162 & .76179 & 168 & .34000 \\
\hline Papua New Guinea & 163 & .75984 & 148 & .46700 \\
\hline Equatorial Guinea & 164 & .75644 & 171 & .33700 \\
\hline Botswana & 165 & .75222 & 169 & .33800 \\
\hline Madagascar & 166 & .74572 & 159 & .39700 \\
\hline Gabon & 167 & .74050 & 139 & .51100 \\
\hline Mozambique & 168 & .73993 & 184 & .26000 \\
\hline Ethiopia & 169 & .73841 & 180 & .27600 \\
\hline Niger & 170 & .73772 & 170 & .33700 \\
\hline Malawi & 171 & .73614 & 185 & .25100 \\
\hline Guinea-Bissau & 172 & .73200 & 176 & .31400 \\
\hline South Africa & 173 & .72956 & 175 & .31900 \\
\hline Djibouti & 174 & .72606 & 157 & .41400 \\
\hline Democratic Rep. Korea & 175 & .72590 & 167 & .35300 \\
\hline Lao People's Dem & 176 & .72555 & 165 & .35600 \\
\hline Eritrea & 177 & .72455 & 158 & .39900 \\
\hline Cambodia & 178 & .72114 & 174 & .32200 \\
\hline Lesotho & 179 & .72040 & 183 & .26600 \\
\hline Swaziland & 180 & .70747 & 177 & .30500 \\
\hline Guinea & 181 & .70066 & 161 & .38500 \\
\hline Chad & 182 & .68813 & 178 & .30300 \\
\hline Nigeria & 183 & .67582 & 187 & .27600 \\
\hline Myanmar & 184 & .67293 & 190 & .13800 \\
\hline Somalia & 185 & .66585 & 179 & .28600 \\
\hline Afghanistan & 186 & .66296 & 173 & .32500 \\
\hline Angola & 187 & .65609 & 181 & .27500 \\
\hline Central African & 188 & .64982 & 189 & .21500 \\
\hline Democratic Repub. Congo & 189 & .64534 & 188 & .17100 \\
\hline Liberia & 190 & .63272 & 186 & .20000 \\
\hline Sierra Leone & 191 & .45812 & 191 & U \\
\hline
\end{tabular}




\section{References}

Aigner, D., K. Lovell, K. and P. Schmidt, "Formulation and Estimation of Stochastic Frontier Function Models," Journal of Econometrics, 6, 1977, pp. 21-37.

Auster, R., I. Levinson and D. Sarachek, "The Production of Health: An Exploratory Study," Journal of Human Resources, 4, 1969, pp. 411-436.

Battese, G. and T. Coelli, "Frontier Production Functions, Technical Efficiency and Panel Data: With Application to Paddy Farmers in India," Journal of Productivity Analysis, 3, 1, 1992, pp. 153-169.

Battese, G. and Coelli, T., "A Model for Technical Inefficiency Effects in a Stochastic Frontier Production Function for Panel Data," Empirical Economics, 20, 1995, pp. 325-332.

Berger, M. and J. Messer, "Public Financing of Health Expenditures, Insurance, and Health Outcomes," Applied Economics, 34, 2002, pp. 2105-2113.

Coelli, T., "A Guide to FRONTIER, Version 4.1: A Computer Program for Stochastic Frontier Production and Cost Function Estimation," CEPA Working Paper 96/7, Department of Econometrics, University of New England, Armidale, New South Wales, Australia.

Cornwell, C., P. Schmidt and R. Sickles, "Production Frontiers with Cross Sectional and Time Series Variation in Efficiency Levels," Journal of Econometrics, 46, 1990, pp. 185-200.

Econometric Software, Inc., "LIMDEP, Version 8.0," ESI, New York, 2002.

Gravelle, H., R. Jacobs, A. Jones, and A. Street, "Comparing the Efficiency of National Health Systems: Econometric Analysis Should be Handled with Care," University of York, Health Economics, UK, Manuscript, 2002

Gravelle, H., R. Jacobs, A. Jones, and A. Street, "Comparing the Efficiency of National Health Systems: A Sensitivity Approach, University of York, Health Economics, Manuscript, UK, 2002.

Greene, W. "Maximum Likelihood Estimation of Econometric Frontier Functions," Journal of Econometrics, 1980.

Greene, W., "A Gamma Distributed Stochastic Frontier Model," Journal of Econometrics, 46, 1, 1990, pp. 141-164.

Greene, W., "Frontier Production Functions," in M. Pesaran and P. Schmidt, eds., Handbook of Applied Econometrics, Volume II: Microeconometrics, Oxford, Blackwell Publishers, 1997.

Greene, W., Fixed and Random Effects in Nonlinear Models, Stern School of Business, Department of Economics, Working Paper 01-01, 2001 on simulated MLE

Greene, W., "Fixed and Random Effects in Stochastic Frontier Models, Stern School of Business, Department Of Economics, Working Paper 02-16, 2002a.

Greene, W., "Fixed Effects and the Incidental Parameters Problem in the Tobit Model," Manuscript, Department of Economics, Stern School of Business, New York University, 2002b.

Greene "Simulated Maximum Likelihood Estimation of the Normal-Gamma Stochastic Frontier Model," Journal of Productivity Analysis, 2003a, forthcoming.

Greene, W., Econometric Analysis, $5^{\text {th }}$ ed., Prentice Hall, Upper Saddle River, 2003b.

Greene, W., "Estimation of a Latent Class Stochastic Frontier Model," manuscript, Department of Economics, Stern School of Business, New York University, 2003c.

Grossman, M., "On the Concept of Health Capital and the Demand for Health," Journal of Political Economy, 80, 1972, pp. 223-255.

Hollingsworth, J. and B. Wildman, "The Efficiency of Health Production: Re-Estimating the WHO Panel Data Using Parametric and Nonparametric Approaches to Provide Additional Information," Health Economics, 11, 2002, pp. 1-11. 
Hsiao, C, " Logit and Probit Models. In The Econometrics of Panel Data: Handbook of Theory and Applications, Second Revised Edition, Matyas, L. and Sevestre, P. (eds.). Kluwer Academic Publishers: Dordrecht, 1996.

Jondrow, J., I. Materov, K. Lovell and P. Schmidt, "On the Estimation of Technical Inefficiency in the Stochastic Frontier Production Function Model," Journal of Econometrics, 19, 2/3, 1982, pp. 233-238.

Kim, Y. and P. Schmidt, "A Review and Empirical Comparison of Bayesian and Classical Approaches to Inference on Efficiency Levels in Stochastic Frontier Models with Panel Data," Journal of Productivity Analysis, 14, 2, 2000, pp. 91-118.

Kumbhakar, S. and K. Lovell, Stochastic Frontier Analysis, Cambridge University Press, Cambridge, 2000.

Kumbhakar, S. and L. Orea, "Efficiency Measurement Using a Stochastic Frontier Latent Class Model," Efficiency Series Papers, University of Oviedo, 2002.

Lancaster, T. "The Incidental Parameters Problem Since 1948," Journal of Econometrics, 95, 2000, pp. 391-414.

Newhouse, J. "Medical Care expenditure: A Cross National Survey," Journal of Human Resources, 12, 1977, pp. 115-124.

Pitt, M. and L. Lee, "The Measurement and Sources of Technical Inefficiency in Indonesian Weaving Industry," Journal of Development Economics, 9, 1981, pp. 43-64.

Polachek, S. and B.Yoon, "Panel Estimates of a Two-Tiered Earnings Frontier," Journal of Applied Econometrics, 11, 1996, pp. 169-178.

Schmidt, P. and R. Sickles, "Production Frontiers with Panel Data," Journal of Business and Economic Statistics, 2, 4, 1984, pp. 367-374.

Segal, D. and W. Greene "Profitability, Growth, and Efficiency in the U.S. Life Insurance Industry," Journal of Productivity Analysis, 2004, forthcoming.

Stevenson, R., "Likelihood Functions for Generalized Stochastic Frontier Functions," Journal of Econometrics, 13, 1980, pp. 57-66.

Train, K., Discrete Choice: Methods with Simulation, Cambridge, Cambridge University Press, 2002.

Tandon, A., Murray, C., Lauer, J. and Evans, D., "The Comparative Efficiency of National Health Systems in Producing Health: An Analysis of 191 Countries," World Health Organization, GPE Discussion Paper, No. 29, EIP/GPE/EQC

Tandon, A., Murray, C., Lauer, J. and Evans, D., "Measuring Overall Health System Performance for 191 Countries," World Health Organization, GPE Discussion Paper, No. 30, $\mathrm{EIP} / \mathrm{GPE} / \mathrm{EQC}$

Wang, H. and P. Schmidt, "One-Step and Two-Step Estimation of the Effects of Exogenous Variables on Technical Efficiency Levels," Journal of Productivity Analysis, 18, 2002, pp. 129-144.

Williams, A., "Science of Marketing at WHO? A Commentary on World Health 2000," Health Economics, 10, 2001, pp. 93-100.

World Health Organization, The World Health Report, 2000, Health Systems: Improving Performance, 2000, Geneva. 